\title{
Límites del principio de estabilidad presupuestaria respecto de la autonomía financiera de las Comunidades Autónomas españolas
}

\section{Limits of the principle of budgetary stability with respect to the financial autonomy of the Spanish Autonomous Communities}

\author{
Carlo Alberto Ciaralli \\ Universidad G. d'Annunzio Chieti - Pescara \\ carlo.alberto.ciaralli@live.it
}

\begin{abstract}
NOTA BIOGRÁFICA
PhD in Constitutional Law - Doctor Europaeus, Universidad G. d'Annunzio Chieti - Pescara. Sus líneas de investigación se centran en el estudio comparativo de los Estados federales y regionales, las relaciones entre la Unión Europea, el Estado y las Regiones, los ordenamientos jurídicos italiano y español.
\end{abstract}

\section{RESUMEN}

España, en el año 2011, modificó el artículo 135 de su Constitución para introducir el principio de Estabilidad Presupuestaria y un intenso control sobre los presupuestos de todas las Administraciones Públicas nacionales, incluidas, en particular, las Comunidades Autónomas, para garantizar las finanzas nacionales y, también, para limitar el gasto público y el déficit estructural. La reforma constitucional ha producido una fuerte centralización del marco normativo en tema de gasto y presupuesto, un renovado papel desempeñado por parte del Estado en función de «control» sobre la autonomía financiera autonómica y la compresión de dicha autonomía financiera, cerrada entre las estrictas normas constitucionales (y su desarrollo posterior mediante una Ley Orgánica) y el control ejercitado por parte del Estado central.

\section{PALABRAS CLAVE}

Estabilidad presupuestaria; sostenibilidad financiera; Comunidades Autónomas; Tribunal Constitucional; Constitución.

\begin{abstract}
The constitutional reform by which in 2011 Spain amended Article 135 of the Constitution is the topic of this article. By such an amendment the principle of financial and budgetary stability as well as a strict control over the budget of public administration and the devolved regional institutions (Comunidades Autonomas) has been introduced. All this amounts to severe limitations on the structural deficit. In fact, this reform has brought about a strengthening of the supervisory powers of the State over policies which the Constitution confers to the Comunidades Autonomas as well as clamping down on their financial autonomy. The thrust of the article is to show how, in time of crisis, the "financial constitution" changes its structure to adapt to the inputs coming from European rules and the financial markets.
\end{abstract}

\section{KEYWORDS}

Budgetary stability; financial sustainability; Autonomous Communities; Constitutional Court; Constitution. 


\section{SUMARIO}

1. EL ORIGEN DE LA REFORMA CONSTITUCIONAL. 2. LA RÁPIDA APROBACIÓN PARLAMENTARIA DE LA REFORMA CONSTITUCIONAL. 3. LA REFORMA DEL ARTÍCULO 135 DE LA CONSTITUCIÓN ESPAÑOLA: EL CONTENIDO DE LA REFORMA. 4. LA LEY ORGÁNICA 2/2012, DE 27 DE ABRIL, DE ESTABILIDAD PRESUPUESTARIA Y SOSTENIBILIDAD FINANCIERA. 4.1. MEDIDAS PREVENTIVAS, CORRECTIVAS Y COERCITIVAS. 5. LA JURISPRUDENCIA DEL TRIBUNAL CONSTITUCIONAL SOBRE EL PRINCIPIO DE ESTABILIDAD PRESUPUESTARIA. 6. CONCLUSIONES. 7. REFERENCIAS BIBLIOGRÁFICAS.

\section{EL ORIGEN DE LA REFORMA CONSTITUCIONAL}

El 27 de septiembre de 2011 se publicó, en el Boletín Oficial del Estado (en adelante BOE), la aprobación de la segunda reforma de la Constitución española de 1978, que modificó su artículo 135, para introducir el principio de Estabilidad Presupuestaria. El mismo afecta a las actuaciones de todas las Administraciones Públicas, permite el control del Estado sobre el presupuesto y el gasto de las Comunidades Autónomas y limita el déficit estructural y el volumen de la deuda pública1.

Como es sabido, la reforma constitucional ${ }^{2}$ se planteó en el marco de las graves tensiones financieras, causadas por la fuerte especulación internacional sobre la deuda pública de algunos Estados miembros de la UE (en particular, Irlanda, España, Italia, Portugal y Grecia), tras la explosión de la burbuja inmobiliaria, que comenzó en Estados Unidos como crisis de la deuda privada y, posteriormente, con efecto de contagio, extendida a todo el Viejo continente, como crisis de la deuda pública de los Estados ${ }^{3}$. Los proponentes de la reforma ${ }^{4}$, para justificar la necesidad de modificar la Constitución, expusieron motivos tanto de carácter económico como político. En particular, con el Spread en rápido crecimiento y la situación financiera, cada vez más deteriorada, se afirmó la urgencia inaplazable de introducir el principio de Estabilidad Presupuestaria en el ordenamiento jurídico español, especialmente a nivel constitucional, con el fin tanto de salvaguardar las finanzas públicas como de fortalecer la economía española ${ }^{5}$, a medio y largo plazo, de cara a los mercados ${ }^{6}$, que obtendrían así, según los proponentes, seguridades y garantías de solidez del estado de las finanzas públicas españolas. En este sentido, «se trataba, por tanto, con la reforma de asumir constitucionalmente el compromiso de que el Reino de España satisfaría las exigencias de disciplina presupuestaria impuestas en

Reforma del artículo 135 de la Constitución Española (BOE núm. 233, de 27-09-2011).

2 La reforma del 2011 es, en orden cronológico, la segunda modificación de la Constitución Española, siendo la primera enmienda de fecha 27 de agosto de 1992 (BOE núm. 207, de 28-08-1992), cuando, en cumplimiento de la ratificación del Tratado de Maastricht, se modificó el artículo 13, apartado segundo, de la Constitución para permitir que cualquier ciudadano de la Unión europea, residente en otro Estado miembro, pueda participar, tanto de forma activa como pasiva, en las elecciones municipales españolas.

3 El Presidente del Gobierno español recibió una carta del Presidente del Banco Central europeo el 5 de agosto de 2011. En ella, en primer lugar, se le recordaba al Presidente del Gobierno que «la cumbre de Jefes de Estado y de Gobierno de la zona euro celebrada el 21 de julio de 2011 concluyó que "todos los países de la zona euro reafirmaron solemnemente su determinación absoluta de hacer plenamente honor a su propia firma soberana y a todos sus compromisos en materia de condiciones presupuestarias sostenibles y reformas estructurales"». En segundo lugar, entrando en el fondo del asunto, el Banco Central europeo pedía al Gobierno español de «apuntalar urgentemente la reputación de su firma soberana y su compromiso con la sostenibilidad fiscal y las reformas estructurales, y hacerlo mediante pruebas creíbles». Para conseguir estos objetivos, se enumeraron unas medidas de carácter político como, por ejemplo, la reforma del mercado laboral (reforma de la negociación colectiva, supresión de las cláusulas de indexación de la inflación, moderación salarial en el sector privado), reformas sobre la sostenibilidad de la finanza pública (medidas adicionales de consolidación fiscal, introducción de nuevas reglas para limitar el incremento de gasto, más trasparencia sobre los presupuestos de los gobiernos autonómicos) y, además, reformas en los sectores energético y de los servicios. Lo que llama la atención, en dicha carta, es el nivel de detalle (análogo a la carta del Banco Central Europeo dirigida al Gobierno italiano) de las reformas que la institución europea (con mayor razón, el Banco Central europeo) pedí al Presidente del Gobierno de España.

4 La propuesta de modificación constitucional, realizada por los dos mayores grupos parlamentarios, populares y socialistas, tuvo lugar justo un mes antes de la aprobación definitiva del texto de la reforma, el 26 de agosto de 2011.

5 Como señala RIDAURA MARTÍNEZ, M. J., "La reforma del artículo 135 de la Constitución española: ¿pueden los mercados quebrar el consenso constitucional?", en Teoría y Realidad Constitucional, núm. 29, 2012, 237 y ss., 237: «el principio incorporado al texto constitucional constituye un principio clásico de la Ciencia de la Hacienda, aunque no exento de controversia; habiendo sido defendido desde finales del Siglo XVIII por los economistas liberales».

6 LÓPEZ AGUILAR, F., "De la Constitución «irreformable» a la reforma constitucional "exprés»", en Teoría y Realidad Constitucional, 29, 2012, 199 y ss., 208-209, afirma que el «contenido (de la reforma que) se anuncia como un "mensaje" de "determinación" y "compromiso" dirigido a "tranquilizar" a los mercados e inversores internacionales ante las turbulencias sufridas por la zona euro a lo largo del verano de ese año (2011)». 
última instancia desde Bruselas; y hacerlo, además, de tal modo que ese compromiso constitucional resultara creíble para los mercados financieros» ${ }^{7}$.

El Estado español ya contaba, anteriormente a la reforma constitucional, con una regulación que preveía el principio de estabilidad presupuestaria, tanto a nivel estatal (Ley 18/2001, de 12 de diciembre, General de Estabilidad Presupuestaria ${ }^{8}$ ) como autonómico (Ley Orgánica 5/2001 de 13 de diciembre, complementaria a la Ley 18/2001, General de Estabilidad Presupuestaria ${ }^{9}$ ). De esta manera, sin embargo, se incorporaba al ordenamiento jurídico interno lo establecido en el Pacto Europeo de Estabilidad y Crecimiento de 1997.

La regulación sobre el principio de Estabilidad Presupuestaria fue aprobada con el objetivo declarado de introducir un nuevo mecanismo para la determinación de la estabilidad de las Administraciones Públicas territoriales y sus respectivos sectores públicos, apoyado en el diálogo y la negociación entre el Estado y las Comunidades Autónomas. Los principios generales que recogía la Ley 18/2001 son los principios de transparencia, plurianualidad y eficiencia en la asignación y utilización de recursos públicos. Además, la Ley 18/2001 sometía al Gobierno, las Comunidades Autónomas y las Entidades Locales a reglas estrictas de contención del gasto. Se establecía que los sujetos ${ }^{10}$ que tenían que respetar la Ley 18/2011 deben contemplar «en sus normas reguladoras en materia presupuestaria los instrumentos y procedimientos necesarios para adecuarlas al objetivo de cumplimiento del principio de estabilidad presupuestaria» y se añade, como garantía del cumplimiento de los principios establecidos, que «corresponde al Gobierno de la Nación, sin perjuicio de las competencias del Consejo de Política Fiscal y Financiera de las Comunidades Autónomas, velar por el cumplimiento del principio de estabilidad presupuestaria en todo el ámbito del sector público» (artículo 7).

Se prevén además normas claras contra el riesgo de incumplimiento de los objetivos declarados en esta Ley. En particular, las situaciones anormales de déficit presupuestario deberán ser justificadas, por la Administración Pública afectada, con una exposición de las causas de este déficit y la formulación de un plan económico-financiero, que efectivamente produzca el saneamiento, a medio plazo, de esta situación presupuestaria.

La Ley Orgánica 5/2001 es una disposición normativa complementaria a la Ley 18/2001, General de Estabilidad Presupuestaria. En dicha Ley Orgánica, se preveían los mecanismos de cooperación entre el Estado y las Comunidades Autónomas para la realización de los principios desarrollados en la Ley 18/2001. De hecho, la Ley Orgánica 5/2001 extienda el principio de Estabilidad Presupuestaria, de forma específica, a las CC.AA., las cuales tenían que cumplir dichos objetivos presupuestarios.

Además, la Ley Orgánica 5/2001 modificó, en el apartado 2 de su Disposición adicional única, el artículo 3, apartado 2, de la Ley Orgánica 8/1980, de 22 de septiembre, de Financiación de las Comunidades Autónomas, para añadir nuevas competencias al Consejo de Política Fiscal y Financiera de las Comunidades Autónomas, fortaleciendo el control estatal sobre el régimen financiero y presupuestario autonómico ${ }^{11}$.

Esta regulación, aunque imponía límites al gasto estatal y autonómico, se planteaba en un marco colaborativo entre el Estado y las CC.AA., definiendo los límites de política presupuestaria y de gasto, desde una óptica bilateral, en el ámbito del Consejo de Política Fiscal y Financiera.

En este sentido, la Ley Orgánica 2/2012, que desarrolla los principios establecidos en el nuevo artículo 135 de la Constitución, ha supuesto una modificación radical.

Es importante subrayar que, de hecho, ya un año antes de la reforma constitucional fue instituida, mediante la Ley $37 / 2010$, de 15 de noviembre ${ }^{12}$, la «Oficina Presupuestaria de las Cortes Generales». La fun-

\footnotetext{
7 MEDINA GUERRERO, M., "La constitucionalización del principio de estabilidad presupuestaria", en Revista de Estudios Regionales, núm. 105, 2016, 73 y ss., 75.

${ }^{8}$ Ley 18/2001, de 12 de diciembre, General de Estabilidad Presupuestaria (BOE núm. 298, de 13-12-2001), modificada por la Ley 15/2006, de 26 de mayo, de reforma de la Ley 18/2001, de 12 de diciembre, General de Estabilidad Presupuestaria (BOE núm. 126, de 27-05-2006).

9 Ley Orgánica 5/2001 de 13 de diciembre, complementaria a la Ley General de Estabilidad Presupuestaria (BOE núm. 299, de 14-12-2001), modificada por la Ley Orgánica 3/2006, de 26 de mayo, de reforma de la Ley Orgánica 5/2001 (BOE núm. 126, de 27-052006).

10 El ámbito de aplicación subjetivo de la Ley 18/2001 incluye todos los organismos del sector público,

11 Se añadieron las siguientes competencias: 1. La emisión de los informes y la adopción de los acuerdos previstos en la Ley Orgánica 18/2001, Complementaria de la Ley General de Estabilidad Presupuestaria; 2. La apreciación de las razones que justifiquen, en cada caso, la percepción por parte de las Comunidades Autónomas de las asignaciones presupuestarias, así como los criterios de equidad seguidos para su afectación; 3. La coordinación de la política de endeudamiento; 4. La coordinación de la política de inversiones públicas; 5 . En general, todo aspecto de la actividad financiera de las Comunidades Autónomas y de la Hacienda del Estado que, dada su naturaleza, precise de una actuación coordinada.

12 BOE núm. 277, de 16-11-2010.
} 
ción del órgano, específica la Ley en su Preámbulo, es «la necesidad de articular en el seno de las Cámaras un mecanismo eficaz de asesoramiento técnico en materia de seguimiento y control de la ejecución de los Presupuestos Generales del Estado y sobre aquellos aspectos que tengan repercusión en los ingresos y gastos públicos, instrumento inspirado en los principios de independencia, objetividad y transparencia que se pone al alcance de los Diputados y Senadores».

\section{LA RÁPIDA APROBACIÓN PARLAMENTARIA DE LA REFORMA CONSTITUCIONAL}

El procedimiento de reforma constitucional del artículo 135 de la Constitución española se tramitó rápidamente y, en la opinión de gran parte de la doctrina ${ }^{13}$, con demasiada celeridad, sin un adecuado debate parlamentario; efectivamente, en un mes se llevó a cabo el procedimiento de modificación del artículo 135 de la Constitución española.

La gran mayoría de las enmiendas presentadas fueron inadmitidas y las admitidas todas rechazadas. El texto no fue sometido a referéndum ya que no lo solicitaron una décima parte de los miembros del Congreso ni del Senado, como exige el art. 167, apartado tercero, de la Constitución española. De hecho, en el momento de la presentación de la propuesta de reforma constitucional, los proponentes pidieron la tramitación por el procedimiento de urgencia, así como su aprobación mediante la lectura única por el Pleno de las Cortes Generales.

Además, junto a la presentación de la propuesta de revisión del artículo 135 de la Constitución, fue presentada otra propuesta, por mayoría absoluta de los miembros de la Cámara, por la cual, basándose en los artículos 73, apartado 2, de la Constitución y al artículo 61 del Reglamento del Congreso de los Diputados, se pedía la convocatoria del Pleno de la Cámara en sesión extraordinaria, para lograr la discusión y aprobación del texto de reforma constitucional mediante un procedimiento acelerado de urgencia, en lectura única.

Los Reglamentos de ambas Cámaras del Parlamento regulan, como un procedimiento legislativo especial, el procedimiento rápido de lectura única, que, a propuesta de la Mesa, puede ser elegido por el Pleno de la Cámara, previa consulta de la Junta de Portavoces de los grupos parlamentarios. La aplicación de dicho procedimiento especial está prevista y, también, limitada tanto en el Reglamento del Congreso (art. 150), como en el Senado (art. 129) para los proyectos o proposiciones legislativas cuya «naturaleza lo aconseje o cuya simplicidad de formulación lo permita».

En particular, sobre la insuficiente claridad de dicha formulación, presente en los dos Reglamentos antes mencionados, se señala que «la ambigüedad de esta determinación ha hecho que sea normalmente utilizado cuando exista un consenso tal sobre el contenido que es previsible que el texto no se vaya a variar en el curso de la tramitación (sea o no simple su contenido), previo acuerdo de la Junta de Portavoces» y se añade que, en la práctica parlamentaria, se utiliza este procedimiento «básicamente en tres casos: a) para la tramitación de proyectos o proposiciones de ley muy breves y sencillas, básicamente consensuadas, que sería la previsión reglamentaria; b) para la tramitación de proyectos o proposiciones sobre los que recae acuerdo unánime de tramitación particularmente acelerada por urgencia política en la promulgación de la ley. Estos proyectos o proposiciones han llegado a culminar su tramitación en una semana en cada Cámara, cuando existe una voluntad política en este sentido (por ejemplo, medidas para víctimas del terrorismo); c) cuando se opta por este procedimiento, o así lo impone una ley, por introducirse un elemento pactista en la elaboración del proyecto o proposición» ${ }^{14}$.

Otra parte de la doctrina resaltando, en tono crítico, la insuficiente claridad de la norma cree que nunca una reforma constitucional "debiera ser contemplada desde la "simplicidad de su formulación" y mucho menos en el supuesto de la llevada a cabo en 2011, en la que, como estoy subrayando, se ponían en juego tantos elementos esenciales de nuestro Estado Constitucional» ${ }^{15}$. Dicho procedimiento, de hecho, facilita

13 Sobre el tema específico del procedimiento parlamentario de tramitación de la reforma del artículo 135 de la Constitución española véase, por todos, GARCÍA-ESCUDERO MÁRQUEZ, P., "La acelerada tramitación parlamentaria de la reforma del artículo 135 de la Constitución", en Teoría y Realidad Constitucional, núm. 29, 2012, 165 y ss.; RIDAURA MARTíNEZ, M. J., "La reforma del artículo 135 de la Constitución española: ¿pueden los mercados quebrar el consenso constitucional?”, op. cit., 237 y ss., espec. 249 y ss., donde se plantean fuertes dudas sobre la «idoneidad» del procedimiento mismo; LÓPEZ AGUILAR, F., "De la Constitución «irreformable» a la reforma constitucional «exprés»", op. cit., 199 y ss. En particular, LóPEz AGUILAR utiliza, en tono sugerente, el término «exprés», para subrayar la anomalía de un procedimiento tan rápido de modificación de la Constitución.

14 GARCÍA-ESCUDERO MÁRQUEZ, P., "La acelerada tramitación parlamentaria de la reforma del artículo 135 de la Constitución", op. cit., 173-174.

15 SALAZAR BENÍTEZ, O., "La Constitución domesticada: algunas reflexiones críticas sobre la reforma del artículo 135 CE", en Teoría y Realidad Constitucional, núm. 29, 2012, 409 y ss., 414. 
los trabajos parlamentarios; pero, en realidad, suprimiendo la fase de análisis y discusión en las comisiones parlamentarias competentes, provoca la votación del proyecto de ley, en el Pleno, sin una adecuada evaluación del proyecto mismo. Dada la particularidad del procedimiento de reforma, se afirmó, en tono crítico, que «la Reforma se aprobó sin apenas debate parlamentario (en solo 2 horas y 40') y siguiendo una tramitación a caballo de dos procedimientos especiales: lectura única y por el procedimiento de urgencia, es decir, a la carrera (...). La tramitación elegida no tiene sentido alguno desde la lógica del parlamentarismo dada la entidad de una reforma constitucional» ${ }^{16}$.

Además, muchas críticas de la doctrina se refirieron a la ruptura del «consenso constitucional», que acompañó la aprobación de la Constitución española de 1978. Consenso constitucional que requería el beneplácito de la gran mayoría, si no de la casi totalidad, de las fuerzas políticas parlamentarias. En este sentido específico, se afirmó que «la reforma se fundó en un acuerdo bipartidista que rompió el consenso que mostraron nuestros "padres fundadores" al redactar la Constitución del 1978 (...). La tramitación récord, en apenas quince días, aprovechando el procedimiento de urgencia y en lectura única, sin admisión de enmiendas de otros grupos y sin participación de organismos consultivos procuró limitar al máximo el debate público, no permitiendo extraer otra conclusión de la reforma que no sea la banalización de la idea misma de Constitución a que condujo un bólido que atropello a un Parlamento vencido y que esperaba el breve plazo de su oficial disolución» ${ }^{17}$.

El punto más criticado, en realidad, no es solamente el contenido de la reforma, sino más bien la rápida aprobación que, ciertamente, impidió un verdadero debate en Parlamento y en el país.

La reforma, además, ha producido otro efecto. Hasta el 2011 nunca en la Constitución española se había aludido a la Unión Europea como institución, ni tampoco a los Tratados europeos. Efectivamente, la reforma de 1992 del artículo 13, apartado segundo, de la Constitución española no había hecho mención a la Unión Europea.

Como se ha precisado, la reforma constitucional de 2011 implicó «que por la puerta falsa de la reforma del artículo 135 se haya introducido en la Constitución la primera mención a la Unión Europea» ${ }^{18}$. Como hemos visto, el procedimiento de revisión constitucional fue legal y respetó la regulación jurídica establecida por la Constitución y los Reglamentos de las dos Cámaras. En este sentido, «desde el punto de vista el respecto a la vía procedimental del artículo 167 CE ha sido escrupuloso puesto que la solicitud de referéndum no fue aprobada por la décima parte de los miembros de cualesquiera de las dos Cámaras, mínimo establecido en el apartado 4 del artículo 167 CE para que la reforma constitucional tenga que ser sometida a referéndum» ${ }^{19}$.

Sin embargo, queda claro para la mayor parte de la doctrina el hecho que, en el caso de reformas constitucionales (en particular, reformas que modifican el marco de las relaciones entre el Estado y las Comunidades Autónomas y afectan, como veremos, fuertemente a las competencias autonómicas) habría sido conveniente un procedimiento más participado y debatido, con una mayor profundización del tema y, también, con una proyección de los efectos de dicha reforma en el ámbito de las relaciones entre el Estado y las Autonomías territoriales.

16 GARCÍA ROCA, J., "El principio de estabilidad presupuestaria y la consagración constitucional del freno al endeudamiento", en Crónica presupuestaria, 1, 2013, 40 y ss., 67.

17 MARTÍNEZ LAGO, M. A., "Constitucionalización del principio de estabilidad presupuestaria en la Unión europea y en España. La Ley Orgánica de Estabilidad Presupuestaria y Sostenibilidad Financiera”, en GARRIDO, D. L. - MARTíNEZ ALARCÓN, M. L. (coords.), Reforma constitucional y estabilidad presupuestaria, Madrid, 2013, 131 y ss., 153 - 154. En contra, RODRÍGUEZ BEREIJO, A., "La reforma constitucional del artículo 135 CE y la crisis financiera del Estado", en Crónica presupuestaria, 1/2013, 5 y ss., 12, afirma que "convendría no dejarse llevar por un wishful thinking cuando apelamos al "consenso constitucional de 1978", vistos los cambios profundos y el evidente deterioro de nuestra realidad política e institucional así como las menguantes muestras de lealtad a nuestra la Constitución en los últimos tiempos por parte de los partidos nacionalistas que han planteado abiertamente la cuestión constituyente de la inserción en España de Cataluña y el País Vasco con propuestas separatistas de creación de un Estado propio independiente, lo que muestra una grave erosión, acaso irreversible, del consenso constitucional originario».

18 GARCÍA-ESCUDERO MÁRQUEZ, P., "La acelerada tramitación parlamentaria de la reforma del artículo 135 de la Constitución", op. cit., 198. La reforma del artículo 135 ha introducido, de hecho, la primera mención expresa de la Unión Europea, aunque ya la disposición del artículo 93 CE («Mediante la ley orgánica se podrá autorizar la celebración de tratados por los que se atribuya a una organización o institución internacional el ejercicio de competencias derivadas de la Constitución. Corresponde a las Cortes Generales o al Gobierno, según los casos, la garantía del cumplimiento de estos tratados y de las resoluciones emanadas de los organismos internacionales o supranacionales titulares de la cesión») ha sido interpretado como una «cláusula Europa».

19 RODRÍGUEZ BEREIJO, Á., La Constitución fiscal de España. Tres estudios sobre Estado social de Derecho, sistema tributario, gasto público y estabilidad presupuestaria, Madrid, 2005, 307-308. 


\section{LA REFORMA DEL ARTÍCULO 135 DE LA CONSTITUCIÓN ESPAÑOLA: EL CONTENIDO DE LA REFORMA}

El artículo $135^{20}$ de la Constitución española, según la formulación anterior a la reforma, constituye una disposición jurídica empleada en numerosas ocasiones a lo largo de la historia constitucional española; de hecho, ha estado presente, mediante diferentes formulaciones, en todos los textos de la historia constitucional española ${ }^{21}$. Debido a esta peculiaridad, la reforma del artículo 135 de la Constitución española consigue una importancia inédita en el ordenamiento jurídico español. Adentrándonos en el contenido de la reforma constitucional, ha de señalarse que dicha modificación, en primer lugar, vincula a todas las Administraciones Públicas (135.1 CE) al cumplimiento del principio de Estabilidad Presupuestaria.

Se introduce la prohibición, tanto para el Estado como para las Comunidades Autónomas, de incurrir en un déficit estructural que supere los márgenes establecidos por la Unión Europea, remitiendo a una Ley Orgánica posterior el desarrollo de los principios constitucionales, incluida la fijación de los límites máximos, en términos de déficit, admisible para el Estado y las Comunidades Autónomas, en relación con sus propios Productos Interiores Brutos (135.2 CE). Sin duda, es de primordial importancia que el reformado artículo 135 CE se refiera específicamente a los criterios establecidos por el Tratado de Funcionamiento de la Unión Europea ${ }^{22}$, como punto de referencia para la apropiada relación entre el Producto Interior Bruto y la deuda pública ${ }^{23}$. El Estado y las Comunidades Autónomas necesitan una autorización legislativa para emitir deuda pública o contraer crédito. Se otorga la máxima prioridad de pago a los intereses y al capital de la deuda pública de las Administraciones Públicas (art. 135.3 CE).

Esta disposición, en particular, no está exenta de varias consideraciones críticas. Si bien la prioridad de pago ha sido vista como una forma de garantía frente a los mercados, conviene destacar que «con el establecimiento de esta regla de prioridad "absoluta" se está introduciendo una prelación de pagos al margen de las operaciones legalmente establecidas, con lo cual cabría la posibilidad de plantearse si de esta forma podrían quedar marginadas $\mathrm{o}$, incluso, preteridas obligaciones ex lege de carácter contractual o aquellas otras derivadas de resoluciones judiciales. La conclusión es que ello podría conducir a una discriminación subjetiva de acreedores a causa del cumplimiento del objetivo final que no pude ser otro que la preservación del equilibrio presupuestario» ${ }^{24}$.

También en el apartado tercero del artículo 135 se citan los parámetros establecidos por la Unión Europea, en cuanto se específica que el volumen de deuda pública agregado de todas las Administraciones Públicas en relación con el Producto Interior Bruto del Estado no podrá superar el valor de referencia establecido en el Tratado de Funcionamiento de la Unión Europea ${ }^{25}$.

20 Para conocer los comentarios a la disposición constitucional, según la redacción anterior a la reforma de 2011, véase TEJERIZO LÓPEZ, J. M., "Comentario al Artículo 135: Deuda Pública", en ALZAGA VILLAAMIL, O. (coord.), Comentario a la Constitución española del 1978, Madrid, 1996, 345 y ss.; DE LA HUCHA CELADOR, F., "Comentario al Artículo 135 de la Constitución", en CASAS BAAMONDE, M. E. - Rodríguez Piñero y BRAVO FERRER, M. (coords.), Comentarios a la Constitución española, Madrid, $2009,2.049$ y ss.; CAZORLA PRIETO, L. M., "Comentario al Artículo 135 de la Constitución española”, en GARRIDO FALLA, M. (coord.), Comentarios a la Constitución, Madrid, 1985, 2.054 y ss.

21 Consúltense los artículos 355 de la Constitución del 1812, 75 de la Constitución del 1837, 78 de la Constitución del 1845, 104 de la Constitución del 1869, 87 de la Constitución del 1876, 118 de la Constitución del 1931.

22 De hecho, en virtud del artículo reformado $135 \mathrm{CE}$ ha sido establecido un «retorno automático» a los parámetros establecidos por el Tratado de Funcionamiento de la Unión Europea, con el objetivo del correcto cálculo de la relación que debe existir entre la deuda pública y el Producto Interior Bruto; en efecto, una constitucionalización de los parámetros económicos previstos en fuentes del Derecho externas a la Constitución.

${ }^{23}$ Con especial referencia a la influencia de la disciplina presupuestaria de la Unión Europea en los Estados miembros y sobre la redefinición del concepto de «gobernanza económica-financiera» europea véase, por todos, BAR CENDÓN, A., "La reforma constitucional y la gobernanza económica de la Unión europea”, en Teoría y Realidad Constitucional, núm. 30, 2012, 59 y ss.; CLOSA MONTERO, C., "Los cambios institucionales en la gobernanza macroeconómica y fiscal de la UE: hacia una mutación constitucional europea", en Revista de Estudios Políticos (nueva época), núm. 165, julio-septiembre (2014), 65 y ss.; COSIMO, E. D., "En búsqueda de la soberanía perdida. EI principio del equilibrio presupuestario entre la coordinación constitucional y la reforma de la gobernanza económica de la unión europea", en ÁLVAREZ CONDE, E. - SOUTO GALVÁN, C. (coords.), La constitucionalización de la estabilidad presupuestaria, Madrid, 2012, 85 y ss.

${ }_{24}$ CARRILLO, M., "Constitución y control de las finanzas públicas", en Revista Española de Derecho Constitucional, núm. 101, mayo-agosto (2014), 13 y ss., 29. En el mismo sentido, véase DE LA HUCHA CELADOR, F., "La reforma del artículo 135 de la Constitución: Estabilidad presupuestaria y deuda pública", en Revista Española de Derecho Financiero, núm. 153/2012, 21 y ss.

25 El artículo 135 de la Constitución reformada también establece que los parámetros referidos se pueden «superar» sólo en caso de catástrofes naturales, recesión económica o situaciones de emergencia extraordinaria que escapen al control del Estado y perjudiquen de manera considerable la situación financiera o la sostenibilidad económica o social del Estado, mediante el voto favorable de la mayoría absoluta de los miembros del Congreso de los Diputados (art. 135.4 CE). 
La reforma constitucional ha, de igual manera, remitido a la Ley Orgánica el papel de desarrollar los principios contenidos en el reformado artículo 135 de la Constitución, así como «la participación, en los procedimientos respectivos, de los órganos de coordinación institucional entre las Administraciones Públicas en materia de política fiscal y financiera. En todo caso, regulará: a) La distribución de los límites de déficit y de deuda entre las distintas Administraciones Públicas, los supuestos excepcionales de superación de los mismos y la forma y plazo de corrección de las desviaciones que sobre uno y otro pudieran producirse; $b$ ) La metodología y el procedimiento para el cálculo del déficit estructural; c) La responsabilidad de cada Administración Pública en caso de incumplimiento de los objetivos de Estabilidad Presupuestaria» (art. 135.5 CE).

La reforma constitucional, además, «con la fijación de límites explícitos de déficit y deuda públicos, ha venido a reforzar la posición central del Estado y sus competencias en lo que respecta tanto a la definición de los objetivos de Estabilidad Presupuestaria como a las facultades de intervención, supervisión y control de la política financiera (presupuestaria) de las Comunidades Autónomas en orden al cumplimento de dichos límites, constriñendo su autonomía mucho más allá de lo que hubiera permitido el titulo competencial de ordenación de la economía del artículo 149.1.13 CE)» ${ }^{26}$.

En primer lugar, un sector de la doctrina cuestiona la verdadera necesidad de modificar la Carta Magna, para introducir el principio de Estabilidad Presupuestaria ${ }^{27}$. En realidad, las dudas que se plantean es si hacía falta esta reforma constitucional, constitucionalizando la regla de la Estabilidad Presupuestaria, para conseguir el objetivo de fortalecer el estado de las finanzas españolas. Sobre dicho punto, se plantean dudas, debido a que, como hemos visto antes, «la fijación de una política de Estabilidad Presupuestaria ya se contenía en la legislación, que reconocía desde 2001 importantes facultades al Estado central posibilitando penetrar en el ámbito de la autonomía financiera de las Comunidades Autónomas» ${ }^{28}$.

Respecto a la cuestión de la «constitucionalización» de la regla de oro europea, es decir, la tramitación e incorporación constitucional de la normativa pactada por España en sede supranacional, un sector de la doctrina no cree que, con la reforma constitucional, las reglas financieras hayan obtenido completamente rango constitucional, en cuanto estas reglas no están planteadas en el Derecho originario de la Unión Europea. En este sentido, se específica "sin embargo, que este "Pacto Fiscal" (el Tratado de Estabilidad, Coordinación y Gobernanza en la Unión Europea), pese a sus múltiples puntos de conexión e interrelación con la Unión Europea tanto en el plano normativo como institucional, no es estrictamente Derecho europeo originario, sino que su naturaleza jurídica es la de un "mero" acuerdo internacional. Por consiguiente, los nuevos compromisos asumidos por España en el Pacto Fiscal no tienen rango constitucional, habida cuenta de que queda extramuros de la norma de remisión del primer párrafo del art. $135.2 \mathrm{CE}{ }^{29}$.

No obstante, se puede efectivamente afirmar que las reglas presupuestarias, aunque no tienen rango constitucional, integran perfectamente un parámetro de constitucionalidad, para «juzgar los límites sobre el déficit estructural y el volumen de deuda pública asumida por el conjunto de las Administraciones Públicas (art. $135.2 \mathrm{CE})^{30} »$.

${ }^{26}$ RODRÍGUEZ BEREIJO, Á., La Constitución fiscal de España. Tres estudios sobre Estado social de Derecho, sistema tributario, gasto público y estabilidad presupuestaria, op. cit., 322

${ }_{27}$ Se ha debatido en la doctrina si el artículo 40, apartado primero, de la Constitución española, en el que se habla de «estabilidad económica» («Los poderes públicos promoverán las condiciones favorables para el progreso social y económico y para una distribución de la renta regional y personal más equitativa, en el marco de una política de estabilidad económica»), pueda incluir, en una interpretación extensiva del texto constitucional, la necesidad de garantizar el principio de Estabilidad Presupuestaria. A favor véase GARCÉS SANAGUSTÍN, M., "En torno al concepto de estabilidad presupuestaria en España", en GARCÉS SANAGUSTíN, M. (coord.), La estabilidad presupuestaria en el Derecho español, Madrid, 2004, 19 y ss., espec. 27 y ss. En contra, considerando «extravagante» la interpretación del origen del principio de estabilidad presupuestaria en al artículo 40 CE, GARCÍA ROCA, J., "El principio de estabilidad presupuestaria y la consagración constitucional del freno al endeudamiento", op. cit., 55. En este último sentido, también AGUIAR DE LUQUE, L. - ROSADO IGLESIAS, G., "La estabilidad presupuestaria y su eventual proyección en el Estado de las Autonomías", en Cuadernos de Derecho Público, núm. 12, enero-abril, 2001, 9 y ss.

${ }^{28}$ URRUTIA LIBARONA, I., "Crisis económica, estabilidad presupuestaria y recentralización de competencias", en NOGUEIRA LÓPEZ, A. - LOIS GONZÁLEZ, M. I. - DIZ OTERO, I. (coords.), Crisis, Derechos Sociales e Igualdad, Valencia, 2015, 65 y ss., 80-81.

29 MEDINA GUERRERO, M., "La constitucionalización del principio de estabilidad presupuestaria", op. cit., 80.

30 CARRILLO, M., "Constitución y control de las finanzas públicas", op. cit., 18. En el mismo sentido RODRÍGUEZ BEREIJO, A., La Constitución fiscal de España. Tres estudios sobre Estado social de Derecho, sistema tributario, gasto público y estabilidad presupuestaria, op. cit., 346, según el cual «el Derecho comunitario, al que se remite la Ley como valor de referencia, no se convierte per se en norma constitucional de nuestro Derecho interno, aunque si constituirá un elemento cualificado en la interpretación de los límites constitucionales derivados del principio (...) Los límites establecidos por los márgenes de Unión europea y el valor de referencia del TFUE a los que se remite expresamente el artículo 135 CE se convierten en integrantes de los parámetros de constitucionalidad que han de ser tenidos en cuenta al enjuiciar las leyes, disposiciones o actos en materia financiera y presupuestaria». 
En relación con la naturaleza jurídica de las reglas presupuestarias y financieras, se afirmó, en tono crítico, que «la reforma constitucional del artículo 135 CE entraña una cesión de soberanía en materia financiera y presupuestaria a la Unión Europea (Comisión, Consejo y Banco Central Europeo) que refuerza el gobierno económico de la UE ampliando sus potestades de coordinación de las políticas económicas nacionales y de supervisión sobre los Presupuestos de los Estados miembros de la zona del euro en orden a asegurar la sostenibilidad de las finanzas públicas. Es una decisión que altera el equilibrio de la división de poderes entre Parlamento y el Gobierno en materia presupuestaria ${ }^{31}$ (art. $134 \mathrm{CE}$ )». En el mismo sentido, con particular atención a la incorporación en el texto constitucional de las reglas europeas, se ha sostenido que «si el compromiso y la obligación jurídica estaban ya presentes en el Derecho Europeo, su incorporación a la Constitución como prohibición o freno al endeudamiento debe verse sobre todo como un indicio del intenso grado de vinculación a este compromiso» ${ }^{32}$. En realidad, el papel central del Parlamento en la política presupuestaria, en la época de la globalización y de las reglas de la Unión Europea, parece desvalorada y la reforma del artículo 135 refleja claramente que los compromisos con las Instituciones europeas imponen seguir reglas sobre el gasto y respectar el presupuesto que el Parlamento nacional no puede ignorar o, igualmente, alterar. La novedad es que estas reglas, ahora, son parámetros de constitucionalidad de las leyes, por lo que ninguna disposición jurídica podrá desplegar plenamente sus efectos sin tener en cuenta que la Constitución pone un límite fuerte a la capacidad financiera y presupuestaria del Estado y de las Comunidades Autónomas. En efecto, si el Estado es responsable frente a las instituciones supranacionales, «las autoridades centrales de los Estados desempeñan la función de trasladar a los entes regionales y locales los objetivos de déficit público y deuda pública fijados en el marco de la Unión Europea, y de supervisar el cumplimiento por aquellas de dichos objetivos ${ }^{33}$. Debe destacarse la fuerza que desempeña el nuevo marco constitucional sobre la gestión de los presupuestos y del gasto público. Así, se afirma, conectando estrechamente la reforma a la integración de España en la Unión Europea, que «la Estabilidad Presupuestaria no está, sin embargo, limitada al reparto de competencias financieras entre los diferentes órdenes de gobierno. En este sentido, el nuevo artículo $135 \mathrm{CE}$ confirma algo que se ha convertido en un lugar común, y es que la integración de España en la Unión Europea ha dado lugar a una auténtica transformación del Derecho Financiero, y en particular del derecho del gasto público y del papel del Presupuesto» ${ }^{34}$. En realidad, sin poner en dudas cuanto se ha afirmado, en sentido crítico, por gran parte de la doctrina, otra parte de la doctrina, defendiendo el marco estructural de la reforma constitucional, afirma que «non si può ignorare il fatto che, in assenza di espliciti limiti costituzionali, all'indebitamento e al deficit eccessivo, i governi tendono a spendere senza incrementare corrispettivamente la pressione tributaria. Così facendo si attiva un circolo non virtuoso in cui i disavanzi crescono continuamente e nel quale la sopravvivenza dello Stato viene gravemente compromessa» ${ }^{35}$.

\section{LA LEY ORGÁNICA 2/2012, DE 27 DE ABRIL, DE ESTABILIDAD PRESUPUESTARIA Y SOSTENIBILIDAD FINANCIERA}

El nuevo artículo 135 de la Constitución (en particular en los apartados segundo, quinto y la disposición adicional única de la reforma constitucional) prevé el desarrollo normativo del contenido de la reforma mediante una Ley Orgánica posterior. En este sentido, fue aprobada la Ley Orgánica 2/2012, de 27 de abril, de Estabilidad Presupuestaria y Sostenibilidad Financiera (en adelante, LOEPSF) ${ }^{36}$.

31 RODRÍGUEZ BEREIJO, A., La Constitución fiscal de España. Tres estudios sobre Estado social de Derecho, sistema tributario, gasto público y estabilidad presupuestaria, op. cit., 320. En el mismo sentido, véase MARTíNEZ LAGO, M. A., "Crisis Fiscal, Estabilidad presupuestaria y reforma Constitucional”, en El Cronista del Estado Social y Democrático de Derecho, núm. 24, 2011,10 y ss., espec. 17, donde habla de una «pérdida de centralidad presupuestaria del Parlamento por una importante desvalorización de la función que corresponde desempeñar anualmente una las leyes del Presupuesto».

32 GARCÍA ROCA, J., "El principio de estabilidad presupuestaria y la consagración del freno al endeudamiento", op. cit., 55.

33 CARRASCO DURÁN, M., "Estabilidad presupuestaria y Comunidades Autónomas", en Revista d'Estudis Autonómics i Federales, núm. 18, octubre (2013), 169 y ss., 172. Sobre la responsabilidad del Estado frente a las Instituciones europeas véase, por todos, GALÁN VIOQUE, R., La responsabilidad del Estado legislador, Barcelona, 2001, espec. 209 y ss.

34 RUIZ ALMENDRAL, V., La reforma Constitucional a la luz de la estabilidad presupuestaria, op. cit., 112. En este sentido, se refiere al nuevo artículo $135 \mathrm{CE}$ como una «cláusula europea» GARCÍA-ANDRADE GÓMEZ, J., "La reforma del artículo 135 de la Constitución española", en Revista de Administración Pública, núm. 187, enero-abril, 2012,31 y ss., espec. 60 y ss.

35 CARMONA CONTRERAS, A. M., "Costituzionalizzazione del principio del pareggio di bilancio e limiti alla sovranità statale: l'esperienza della riforma costituzionale in Spagna", en MARSOCCI, P. (coord.), Partecipazione politica transnazionale, rappresentanza e sovranità nel progetto europeo, Napoli, 2016, 235 y ss., 250.

36 BOE núm. 103, de 30-04-2012, modificada mediante la Ley Orgánica 4/2012, de 28 de septiembre, de modifica la Ley Orgánica 2/2012, de 27 de abril, de Estabilidad Presupuestaria y Sostenibilidad Financiera (BOE núm. 235, de 29-09-2012), la Ley Orgánica 
La LOEPSF, además de desarrollar los principios ya determinados en el nuevo artículo $135 \mathrm{CE}$, establece que, en el caso en que sea imposible conseguir, por parte de todas las Administraciones Públicas ${ }^{37}$, los objetivos de consolidación de los presupuestos y el control del gasto público, el Estado puede poner en marcha una serie de mecanismos para lograr el cumplimiento de las obligaciones establecidas en la Constitución.

En líneas generales, se puede afirmar que la «Ley Orgánica 2/2012 ha establecido un marco de planificación y vigilancia presupuestaria muy estricto para el conjunto de las Administraciones Públicas. En particular, establece procedimientos para la fijación de los objetivos de déficit y de deuda que deben cumplir cada una de ellas y para la vigilancia de su efectivo cumplimiento, diseñando las medidas preventivas que procede aplicar ante riesgos de incumplimiento, así como las medidas correctivas y coercitivas aplicables en las situaciones en las que tales incumplimientos efectivamente se produzcan, tanto en los objetivos en materia de déficit y deuda pública como en lo relativo a la regla del gasto» ${ }^{38}$.

Los tres objetivos declarados de la LOEPSF son: a) garantizar la sostenibilidad financiera de todas las Administraciones Públicas españolas; b) aumentar la confianza en la estabilidad de la economía española y c) fortalecer el compromiso entre el Estado español y la Unión Europea en materia de Estabilidad Presupuestaria.

Sobre la definición del principio de Estabilidad Presupuestaria, se puede afirmar, en primer lugar, que el precepto transcribe lo que ya estableció el artículo 3, apartado 1, litera a), del Tratado de Estabilidad, Coordinación y Gobernanza en la Unión Económica y Monetaria. Sin embargo, es importante poner de manifiesto una primera incoherencia entre dicho Tratado y la Ley Orgánica 2/2012. Ciertamente, «este tratado permite a los Estados, en el inciso b) del mismo artículo 3.1, como principio general, un déficit estructural máximo anual ajustado en función del ciclo del $0,5 \%$ del Producto Interior Bruto a precios de mercado, sin condicionantes. La LOEPSF, sin embargo, ha convertido dicha previsión en la de un déficit estructural cero ajustado del ciclo, que solo admite un déficit del $0,4 \%$ del producto nacional bruto en términos nominales, 0 el establecido en la normativa europea cuando este fuera inferior, condicionado a que dicho déficit se derive de reformas estructurales a largo plazo (art. 11.2) $)^{39}$.

En segundo lugar, el artículo 4 de la LOEPSF contiene la definición ${ }^{40}$ del principio de «Sostenibilidad Financiera ${ }^{41}$, que se traduce en la determinación de los límites máximos de deuda pública de todas las Administraciones Públicas ${ }^{42}$, con base en lo establecido en el artículo 13 de la LOEPSF (en este artículo se puede notar, además, la constante alusión a los valores establecidos por la Unión Europea, en particular la consideración del $60 \%$ del Producto Interior Bruto nacional como valor de referencia del volumen máximo de la deuda pública) y, en definitiva, como control del endeudamiento público ${ }^{43}$.

6/2013, de 14 de noviembre, de creación de la Autoridad Independiente de Responsabilidad Fiscal, de 14 de noviembre (BOE núm. 274 , de 15-11-2013), la Ley Orgánica 9/2013, de 20 de diciembre, de control de la deuda comercial en el sector público (BOE núm. 305, de 21-12-2013) y la Ley Orgánica 1/2016, de 31 de octubre, de reforma de la Ley Orgánica 2/2012, de 27 de abril, de Estabilidad Presupuestaria y Sostenibilidad Financiera (BOE núm. 264, de 01-11-2016). El Desarrollo normativo de la L. O. 2/2012 ha sido completado mediante el Real Decreto 515/2013, de 5 de julio, por el que se regulan los criterios y el procedimiento para determinar y repercutir las responsabilidades por incumplimiento del Derecho de la Unión Europea (BOE núm. 161, de 06-07-2013) y el Real Decreto 701/2013, de 20 de septiembre, de racionalización del sector público (BOE núm. 231, de 26-11-2013).

37 Para profundizar la disciplina de la organización interior del Estado español, se renvía al detallado trabajo de GALÁN VIOQUE, R., "La Administración General del Estado", en GOSALBEZ PEQUEÑO, H. (dir.), El nuevo régimen jurídico del sector público, Madrid, 2016, 153 y ss.

${ }^{38}$ PEMAN GAVIN, J. M., "Crisis económica y cambios institucionales en Europa y en España", en EZQUERRA HUERVA, A. (coord.), Crisis económica y Derecho Administrativo, Cizur Menor (Navarra), 2016, 27 y ss., 57.

39 CARRASCO DURÁN, M., "Estabilidad presupuestaria y Comunidades Autónomas", op. cit., 184

40 La «capacidad para financiar compromisos de gasto presentes y futuros dentro de los límites de déficit, deuda pública y morosidad de deuda comercial conforme a lo establecido en esta Ley, la normativa sobre morosidad y en la normativa europea" y se añade, además, en el mismo artículo, que «existe sostenibilidad de la deuda comercial, cuando el periodo medio de pago a los proveedores no supere el plazo máximo previsto en la normativa sobre morosidad».

${ }^{41}$ En realidad, en el texto constitucional reformado no se hace mención del principio de «Sostenibilidad Financiera». Se habla, de hecho, en el apartado cuarto, de «sostenibilidad económica», con referencia a las situaciones que escapen a la voluntad estatal y puedan afectar «considerablemente la situación financiera o la sostenibilidad económica o social del Estado» y por las cuales se podrían superar los límites de déficit estructural y de volumen de deuda pública.

${ }^{42}$ La asunción de la responsabilidad financiera por las Comunidades Autónomas ya había sido contemplada en el art. 32 (Sostenibilidad presupuestaria de las Administraciones Públicas) de la Ley 2/2011, de 4 de marzo, de Economía Sostenible (BOE núm. 55, de 5 de marzo de 2011).

${ }^{43}$ En este último sentido, véanse, por todos, CARRASCO DURÁN, M., "Estabilidad Presupuestaria y Comunidades Autónomas", op. cit., espec. 186 y ss.; GARCÍA-ANDRADE GÓMEZ, J., La reforma del artículo 135 de la Constitución española, op. cit., 31 y ss.; RIDAURA MARTÍNEZ, M. J., "La reforma del artículo 135 de la Constitución española: ¿pueden los mercados quebrar el consenso constitucional?", op. cit, espec. 239 y ss. 
Además, en el ámbito de la relación entre los principios de Estabilidad Presupuestaria y de Sostenibilidad Financiera y la regla del gasto, es necesario añadir que «esta regla de la sostenibilidad incide en el gasto público, es decir, supone un límite al crecimiento del gasto público en la medida en que, estables los ingresos ordinarios, los tributos, el gasto sólo puede crecer dentro de los límites de la estabilidad, y por lo tanto no se podrá usar la deuda como fuente de financiación» ${ }^{44}$.

En observancia de las previsiones del artículo 135.3 de la Constitución, el artículo 14 de la LOEPSF reafirma el principio de la prioridad absoluta del pago de la deuda pública, cual ulterior garantía al fin de asegurar la sostenibilidad financiera del Estado y evitar el excesivo endeudamiento del mismo.

Con especial referencia, esta vez, al momento de la aplicación a las Administraciones Públicas de los principios de Estabilidad Presupuestaria y Sostenibilidad Financiera, es decir, las condiciones por las cuales se activan las normas que garantizan los principios de Estabilidad Presupuestaria y Sostenibilidad Financiera, se afirma que «son de aplicación únicamente cuando la iniciativa normativa afecte a los gastos o ingresos públicos presentes o futuros debiendo cuantificarse y valorar sus repercusiones y efectos, es decir, tienen un enfoque económico, de tal forma que la iniciativa normativa será de calidad cuando se ajuste a estos principios»; por lo tanto, estas normas no se aplican exclusivamente en caso de afectación del ámbito económico general; al revés tienen una «aplicación con carácter general, considerándolos como indicadores de la economía ya que la norma deberá tener en cuenta el ahorro obtenido respecto a las previsiones alcanzadas, es decir la diferencia entre los recursos previstos y los recursos reales utilizados para alcanzar su objetivo» ${ }^{45}$.

Un sector de la doctrina defiende la reforma constitucional de la autonomía financiera de las Comunidades Autónomas y de su desarrollo normativo, afirmando que «la autonomía de las Comunidades Autónomas no es soberanía; y su autonomía política y financiera cobra pleno sentido constitucional dentro de la unidad de la Nación española. Y la autonomía financiera lo es dentro de la necesaria y obligada coordinación y cooperación con la Hacienda estatal» ${ }^{46}$. Contra esta posición, se específica, siempre sobre la autonomía financiera de las Comunidades Autónomas, que «al Estado central a quien corresponde fijar los objetivos de déficit y deuda de las Comunidades Autónomas y establecer las eventuales sanciones en caso de incumplimiento ${ }^{47}$. La autonomía financiera de las CCAA ha quedado seriamente comprometida si la comparamos con la situación previa. El nuevo marco supone el diseño unilateral del sistema» ${ }^{48}$.

En realidad, la fijación de un nivel máximo de gasto no es en absoluto una novedad, puesto que ya la Ley 18/2001 había previsto que el acuerdo del Gobierno en donde se fijaba el objetivo de Estabilidad Presupuestaria de las diferentes Administraciones determinase el límite de gasto no financiero del Presupuesto del Estado. Es innegable que «la fijación de topes de gasto facilita el cumplimiento de los límites de déficit y endeudamiento global». Es al mismo tiempo indudable que el problema de la correcta aplicación de esta disposición se propone en el momento que «la quiebra de la regla de gasto no conlleva necesaria e inescindiblemente la vulneración de los concretos niveles máximos de déficit y deuda impuestos a la Administración incumplidora»; y además, desde una perspectiva estrictamente constitucional, «nada en el principio de estabilidad presupuestaria configurado en la Constitución autoriza a imponer un nivel de gasto predeterminado, ya sea absoluto, ya sea relativo, en función de la evolución del PIB o de cualquier otro término de referencia» ${ }^{49}$.

El Consejo de Ministros, con base en el artículo 16 de la LOEPSF, fija los objetivos de Estabilidad Presupuestaria en términos de capacidad o necesidad de financiación y los límites de deuda pública. El Gobierno, previa propuesta del Ministerio de Hacienda y Administraciones Públicas (hoy Ministerio de Hacienda y Función Pública ${ }^{50}$ ) y, sucesivamente, mediante un informe del Consejo de Política Fiscal y

${ }^{44}$ ARIAS ABELLÁN, M. D., "Estabilidad presupuestaria y deuda pública: su aplicación a las Comunidades Autónomas", en Revista d'Estudis Autonómics i Federales, núm. 18, octubre, 2013, 126 y ss., 144.

${ }_{45}$ GONZÁLEZ BUSTOS, M. A., "Principios de buena regulación y evaluación de su cumplimiento", en GAMERO CASADO, E. (coord.), Tratado de procedimiento administrativo común y régimen jurídico básico del sector Público, Valencia, 2016, 2.539 y ss., 2.561.

${ }_{46}$ RODRÍGUEZ BEREIJO, Á., La Constitución fiscal de España. Tres estudios sobre Estado social de Derecho, sistema tributario, gasto público y estabilidad presupuestaria, op. cit., 315.

${ }_{47}$ Sobre este tema véase, entre otros, ORDÓÑEZ SOLíS, D., "¿Cómo se derivan entre las Administraciones españolas las responsabilidades financieras por el incumplimiento del derecho de la Unión europea?", en Revista de Derecho comunitario europeo, núm. 51, mayo-agosto, 2015, 537 y ss.

48 URRUTIA LIBARONA, I., "Crisis económica, estabilidad presupuestaria y recentralización de competencias”, op. cit., 84.

49 MEDINA GUERRERO, M., La constitucionalización del principio de estabilidad presupuestaria, op. cit., 93-94.

50 La estructura del anterior Ministerio de Hacienda y Administraciones Pública ha sido recientemente modificada por los Reales Decretos 415/2016, de 3 de noviembre, por el que se reestructuran los departamentos ministeriales (BOE núm. 267, de 04-11-2016) 
Financiera ${ }^{51}$, establece los objetivos de Estabilidad Presupuestaria y de deuda pública para cada Comunidad Autónoma ${ }^{52}$.

A diferencia de la bilateralidad en la determinación de los objetivos presupuestarios que planteaba la disciplina anterior ${ }^{53}$, se desarrolla un nuevo mecanismo, en un marco claramente unilateral, exclusivamente basado en el informe que emita el Consejo de Política Fiscal y Financiera.

Ciertamente, con los mecanismos previstos en los artículos 15 y 16 de la LOEPSF se plantea un modelo con el cual, en relación a la fijación de los objetivos de Estabilidad Presupuestaria y deuda pública «la competencia está exclusivamente atribuida al Estado, que a través de un acuerdo del Consejo de Ministros aprueba los porcentajes de déficit y deuda correspondientes a las Administraciones Públicas, incluida la autonómica, por lo que aquí interesa, sin que esta última pueda intervenir en la decisión ni unilateralmente ni a través del Consejo de Política Fiscal y Financiera, que se limita a informar y por lo tanto a ser oído» ${ }^{54}$.

Además, en relación a esta última afirmación, es innegable que el Estado tiene la competencia en este ámbito, basándose en los artículos 135 y 149 CE, confirmada por el mismo TC. La realidad es que, como se ha correctamente expresado, en el nuevo marco unilateral indicado, «la intervención de las Comunidades Autónomas en la fijación de sus objetivos de déficit y deuda queda reducida a su participación en los informes del Consejo de Política Fiscal y Financiera, e, incluso, no se recoge ninguna participación de aquellas en la determinación de la tasa de referencia que determina la regla de gasto " ${ }^{55}$. Lo que queda claro es que, la combinación entre reforma constitucional del artículo 135 CE y su posterior desarrollo normativo, conduce a la consecuencia de fortalecer «la posición de control y garantía del Estado en los distintos niveles de gobierno, otorgándole incisivas facultades de intervención para corregir y sancionar las políticas de las Administraciones territoriales que incumplan los mandatos de Estabilidad Presupuestaria» ${ }^{56}$.

\subsection{Medidas preventivas, correctivas y coercitivas}

El nuevo procedimiento unilateral del Gobierno central, sobre la política presupuestaria y de gasto, se perfecciona con la previsión de intensos instrumentos preventivos, correctivos y coercitivos, los cuales incluyen medidas que afectan fuertemente a la autonomía de las Comunidades Autónomas ${ }^{57}$.

La Ley Orgánica encarga al Gobierno, en razón de su base competencial, planteada en el artículo 155 de la Constitución española, promover las medidas necesarias para obligar a su cumplimiento forzoso (art. 26 de la L. O. 2/2012, "Medidas de cumplimiento forzoso"), que podrían llegar, previa intimación, a la inter-

y 424/2016, de 11 de noviembre, por el que se establece la estructura orgánica básica de los departamentos ministeriales (BOE núm. 274, de 12-11-2016), instituyendo el nuevo «Ministerio de Hacienda y Función Pública».

51 La disciplina, prevista en la Ley Orgánica 2/2012 de Estabilidad Presupuestaria y Sostenibilidad Financiera, se basa en el informe que emite el Consejo de Política Fiscal y Financiera sobre los objetivos de cada CC.AA. y la evaluación del cumplimento de dichos objetivos. Este procedimiento, con carácter fuertemente unilateral, sobre la política presupuestaria se perfecciona con la previsión de intensos instrumentos preventivos, correctivos y coercitivos, los cuales incluyen medidas que afectan fuertemente a la autonomía de las Comunidades Autónomas.

52 El artículo 15 de la LOEPSF prevé el mismo procedimiento de fijación de los objetivos de estabilidad presupuestaria y deuda pública, pero esta vez relativo al conjunto de todas las Administraciones Públicas.

${ }_{53}$ Específicamente, el artículo único, apartado tres, de la Ley Orgánica 3/2006, de reforma del artículo 5 de Ley Orgánica 5/2001, de 13 de diciembre, complementaria de la Ley General de Estabilidad Presupuestaria.

${ }^{54}$ ARIAS ABELLÁN, M. D., "Estabilidad presupuestaria y deuda pública: su aplicación a las Comunidades Autónomas", op. cit., 151.

55 CARRASCO DURÁN, M., Estabilidad presupuestaria y Comunidades Autónomas, op. cit., 189.

${ }^{56}$ RODRÍGUEZ BEREIJO, Á., La Constitución fiscal de España, op. cit., 310. Sobre la progresiva recentralización de las competencias, a juicio de URRUTIA LIBARONA, I., "Crisis económica, estabilidad presupuestaria y recentralización de competencias", op. cit., 67 , no se puede afirmar que la única causa sea la crisis económica, en cuanto «las tendencias recentralizadoras por parte del Estado central no resultan novedosas por lo que no cabe relacionarlas unívocamente con los contextos de crisis económica». En este sentido, siguiendo el razonamiento, se afirma que «al margen de la vigorosa técnica del control financiero y presupuestario de las Administraciones Públicas por parte del Estado central, en el contexto general de crisis económica, principalmente a partir del año 2010, el Estado ha incidido sobre varios sectores de competencia autonómica a través de normas sobre la base del recurso a títulos trasversales y el ensanchamiento de la normativa básica». Sobre el impacto del Derecho europeo en el Estado autonómico español véase, por todos, ÁLVAREZ GARCÍA, V., "La recentralización de competencias en España por imperativo del derecho europeo", en Revista General de Derecho Constitucional, núm. 18, 2014, 1 y ss.

57 Ejemplares, en el ámbito del proceso de recentralización estatal, son la Ley 27/2013, de 27 de diciembre, de Racionalización y Sostenibilidad de la Administración Local (BOE núm. 312, de 30-12-2013), la Ley 39/2015, de 1 de octubre, del Procedimiento Administrativo Común de las Administraciones Públicas (BOE núm. 236, de 02-10-2015) y la Ley 40/2015, de 1 de octubre, de Régimen Jurídico del Sector Público (BOE núm. 236, de 02-10-2015). Para un comentario, en particular, de la Ley 27/2013 véase, entre todos, GALÁN GALÁN, A., "La aplicación autonómica de la Ley de Racionalización y Sostenibilidad de la Administración Local", en Revista de Estudios de la Administración Local y Autonómica (nueva época), núm. extraordinario, enero (2015), 1 y ss. 
vención del Estado o, en el máximo grado de intensidad, a la suspensión de la Comunidad Autónoma o a la disolución de la Corporación local. Se trata, como ha sido exhaustivamente puesto de manifiesto, de un tipo de «supervisión federal» ${ }^{58}$ del Estado en relación a la autonomía financiera autonómica.

Pasando ahora al análisis de las medidas preventivas, es necesario, en primer lugar, subrayar que todas las medidas recogidas en la LOEPSF prevén, en un sentido de intensidad creciente, la intervención de un órgano de control diferente respecto a los que tienen el deber de aplicar estas medidas, por lo cual «puede afirmarse que estamos en presencia de una cierta tutela adicional a la que con carácter general se regula en la propia CE sobre la ejecución presupuestaria» ${ }^{59}$.

La LOEPSF contempla, en primer lugar, «medidas preventivas» de control del cumplimiento de los objetivos fijados en Constitución y en la LOEPSF. Las medidas preventivas, reguladas en los artículos 18 y 19 , tienen como finalidad concreta prevenir y, además, impedir el incumplimiento de los objetivos de déficit o deuda, o de la regla de gasto.

En primer lugar, el artículo 18 establece que, tras de disponer el deber de seguimiento de los datos de ejecución presupuestaria y de fijar el gasto a los criterios de estabilidad, que en el caso en que el volumen de la «deuda pública se sitúe por encima del $95 \%$ de los límites establecidos en el artículo 13.1 de esta Ley, las únicas operaciones de endeudamiento permitidas a la Administración Pública correspondiente serán las de tesorería». Se trata de una medida preventiva que pretende el cumplimiento del principio de sostenibilidad financiera vigilando el volumen de deuda pública emitida por las Comunidades Autónomas. Esta medida preventiva limita la apelación al crédito por las Comunidades Autónomas, como consecuencia del deber de cumplimiento del principio de sostenibilidad financiera, incluso si esta específica disposición no resulta incluida expresamente en el texto de la modificación constitucional del artículo 135.

En segundo lugar, el Gobierno, en una situación de posible riesgo de incumplimiento de los objetivos de Estabilidad Presupuestaria, de la deuda pública o de la regla de gasto, por parte de cada Administración Pública o de las Comunidades Autónomas, basándose en las previsiones del artículo 19, formulará una «advertencia motivada» a la Administración responsable previa audiencia a la misma. La Administración incumplidora tendrá un mes para adaptar su presupuesto a las sugerencias del Estado y del Consejo de Política Fiscal y Financiera. Si dicha Administración sigue incumpliendo o el Ministerio de Hacienda considera que las medidas adoptadas por parte de la Administración incumplidora son insuficientes para corregir el riesgo, en virtud del segundo apartado del artículo 19 de la LOEPSF se aplicarán las medidas correctivas del incumplimiento.

Se puede afirmar, sin dudas, que la competencia en materia de evaluación de la situación de incumplimiento o riesgo del mismo que pertenece al Estado parece excesivamente discrecional, en cuanto se habrían podido prever «mecanismos concretos de intervención del órgano de colaboración, al que sólo se le informa de la advertencia y de las técnicas concretas que pueden dar lugar a la apreciación de la insuficiencia, incluso si fuera constatada por el Gobierno» ${ }^{60}$.

Como ciertamente se ha señalado, se trata de «una especie de alerta temprana similar a la existente en el Derecho europeo. Si no se adoptan medidas en el plazo de un mes, se pasa a la fase correctiva» ${ }^{61}$.

En cuanto a las medidas correctivas, previstas en los artículos 20 a 24 de LOEPSF, a diferencia de las medidas preventivas que tenían como objetivo prever el riesgo de incumplimiento, éstas tratan de modificar el destino, redireccionándolas, de las finanzas de las Administraciones Públicas afectadas por incumplimiento de los objetivos de Estabilidad Presupuestaria y deuda pública.

En primer lugar, el artículo 20 prevé «medidas automáticas de corrección»; es decir, en el caso en que el Gobierno compruebe el incumplimiento de los objetivos de Estabilidad Presupuestaria, de deuda pública o de la regla de gasto, «todas las operaciones de endeudamiento de la Comunidad Autónoma incumplidora precisarán de autorización del Estado en tanto persista el citado incumplimiento» y prevé, además, la necesidad de un informe favorable del Ministerio de Hacienda y Administraciones Públicas para la concesión de subvenciones o la suscripción de convenios por parte de la Administración central. Estas medidas correcti-

58 La expresión es de MEDINA GUERRERO, M., "El Estado autonómico en tiempos de disciplina fiscal”, en Revista Española de Derecho Constitucional, núm. 98, mayo-agosto, 2013, 109 y ss., 134, que, en particular, habla de «supervisión federal» (incluyendo la coerción federal), hasta sanciones financieras semejantes a las previstas en el procedimiento de déficit excesivo de la UE, pasando incluso por técnicas que guardan alguna afinidad con la «condicionalidad» característica de las ayudas del FMI, pueden detectarse a lo largo de la Ley Orgánica que nos ocupa».

59 ARIAS ABELLÁN, M. D., "Estabilidad presupuestaria y deuda pública: su aplicación a las Comunidades Autónomas”, op. cit., 156.

60 ARIAS ABELLÁN, M. D., "Estabilidad presupuestaria y deuda pública: su aplicación a las Comunidades Autónomas", op. cit., 159.

61 GARCÍA ROCA, J., "El principio de estabilidad presupuestaria y la consagración del freno al endeudamiento", op. cit., 82. 
vas automáticas, no necesitan de un procedimiento específico, aplicándose en el momento de la comprobación del incumplimiento por parte de las Comunidades Autónomas.

No es requerida una autorización estatal para las operaciones de crédito a corto plazo que no sean consideradas financiación exterior, cuando el plan económico-financiero de cumplimiento, elaborado por parte de la Comunidad Autónoma afectada, hubiera sido considerado idóneo por el Consejo de Política Fiscal y Financiera. De la misma manera, se refleja aquí la configuración general de la Ley Orgánica 2/2012. El ejercicio del control de la idoneidad del plan económico-financiero de la Comunidad Autónoma obligada a cumplir los objetivos citados queda en mano del Gobierno central.

Nos encontramos aquí con un problema interpretativo de no secundario nivel, relativo a las causas de aplicación de las medidas correctivas automáticas; pues «estas medidas correctivas se aplican también en situación de riesgo a través de la advertencia prevista en el artículo 19 (...) Por el contrario, los preceptos que regulan las correctivas las vinculan a situaciones de verificación del incumplimiento» ${ }^{62}$.

La Ley establece que estas medidas automáticas de corrección pueden aplicarse no sólo en caso de expresa comprobación del incumplimiento por parte de la Comunidad Autónoma afectada, sino también a las situaciones de «riesgo» de incumplimiento. Queda claro que, aquí, tiene lugar otra, evidente, injerencia de las autoridades centrales en la disciplina presupuestaria autonómica, en cuanto el simple riesgo ya es suficiente para adoptar medidas de corrección automáticas, establecidas por parte del Estado.

En el caso en que se produzca una desviación en la aplicación de las medidas correctivas, el Ministerio de Hacienda y de Administraciones Públicas podrá pedir a la Administración afectada un ajuste del plan presentado, incluida la adopción de nuevas medidas. Si en el informe siguiente persiste el incumplimiento, se podrán aplicar las medidas coercitivas para garantizar el cumplimiento por parte de la Comunidad Autónoma afectada.

Finalmente, llegando a las medidas «coercitivas» de cumplimiento de los objetivos presupuestario y de deuda pública, hay que abordar el tema precisando las condiciones que legitiman la utilización de dichas medidas.

En particular, se puede proceder con la adopción de las medidas coercitivas antes la «falta de presentación, falta de aprobación o de incumplimiento del plan económico-financiero o del plan de reequilibrio, o cuando el periodo medio de pago a los proveedores de la Comunidad Autónoma supere en más de 30 días el plazo máximo de la normativa de morosidad durante dos meses consecutivos a contar desde la comunicación prevista en el artículo $20.6 »^{63}$. Queda claro que las medidas coercitivas representan la forma de injerencia más grave en el ámbito de la autonomía financiera de las Comunidades Autónomas, constitucionalmente garantizada.

En el caso en que se produzca una situación de incumplimiento, el artículo 25 de la LOEPSF obliga a la Comunidad Autónoma incumplidora a: a) aprobar, en el plazo de 15 días desde que se produzca el incumplimiento, la no disponibilidad de créditos y efectuar la correspondiente retención de créditos, que garantice el cumplimiento del objetivo establecido; $b$ ) constituir, cuando se solicite por el Ministerio de Hacienda y Administraciones Públicas, un depósito con intereses en el Banco de España equivalente al 0,2 \% de su Producto Interior Bruto nominal.

Es importante resaltar la previsión que somete las competencias normativas de las Comunidades Autónomas al cumplimiento de los compromisos de consolidación fiscal de la Unión Europea. Al respecto, la Ley indica que «las competencias normativas que se atribuyan a las Comunidades Autónomas en relación con los tributos cedidos pasarán a ser ejercidas por el Estado» en el supuesto en que estas competencias autonómicas sean causa del incumplimiento de los deberes estatales frente a la Unión Europea. En este sentido, se habla de la sustitución de «la voluntad de la Comunidad Autónoma expresada por el órgano que ejecuta el presupuesto respecto a esta ejecución en los términos aprobados en la Ley de presupuestos, pero no sólo eso, sino que también las competencias normativas correspondientes a los Parlamentos autonómicos pasan a ejercerse por el órgano legislativo estatal cuando sea necesario dar cumplimiento a los compromisos con la Unión Europea en esta materia sin especificar mínimamente

62 ARIAS ABELLÁN, M. D., "Estabilidad presupuestaria y deuda pública: su aplicación a las Comunidades Autónomas", op. cit., 159-160.

${ }_{63}$ Art. 25 LOEPSF. A juicio de MEDINA GUERRERO, M., "El Estado autonómico en tiempos de disciplina fiscal”, op. cit., 139, nota 64 , estas medidas podrán aplicarse también «en relación con aquellas CC.AA. que reciban fondos del mecanismo adicional de financiación previsto en la Disposición adicional primera LOEP, en el caso de que no presenten, no se valoren favorablemente o, sencillamente, incumplan los planes de ajuste que están obligadas a realizar». 
ese presupuesto, que es amplio y que puede llevar a la aplicación de criterios de oportunidad y no de estricta legalidad» ${ }^{64}$.

En el caso en que no se adopten las medidas previstas en la letra a) del artículo 25, o éstas resultaran insuficientes, el Gobierno podrá enviar una «comisión de expertos» para la evaluación del incumplimiento de la Comunidad Autónoma y el estado real de su desequilibrio presupuestario. Dicha comisión elaborará una propuesta que contenga medidas para garantizar el cumplimiento de los objetivos presupuestarios y de deuda pública. Estas medidas no se plantean como consejos a los organismos políticos de la CC.AA. De hecho, las medidas propuestas serán de obligado cumplimiento para la Administración incumplidora.

Sobre esta debatida disposición, se ha afirmado que «el carácter vinculante de la propuesta que formulen "los hombres de negro" enviados por el Ministerio es, sin duda, el aspecto más controvertido del artículo 25.2 LOEPSF. (...) El artículo 135 CE no autoriza una injerencia de esa naturaleza y tampoco el artículo 155 $\mathrm{CE}$, pues la intervención del Ministerio y de la comisión de expertos se presenta como una fase previa a la utilización de este recurso extraordinario» ${ }^{65}$.

Sin embargo, dicha disposición plantea muchas dudas de compatibilidad con los principios constitucionales de autonomía financiera autonómica y la garantía del marco de distribución competencial: de hecho, como se ha indicado «parece evidente que, en substancia, se afecta en manera enorme la autonomía financiera de las Comunidades Autónomas, en particular por el hecho que «resulta más que dudoso que se considere compatible con la autonomía esa atribución prácticamente en blanco a un órgano que parece incardinarse en la estructura jerárquica de la Administración del Estado» ${ }^{66}$

El artículo 26 de la LOEPSF contiene la que más afecta a la autonomía financiera de las Comunidades Autónomas, las «medidas de cumplimiento forzoso». Las condiciones necesarias para poner en marcha estas medidas son: 1) que la Comunidad Autónoma afectada no haya adoptado el acuerdo de no disponibilidad de créditos [art. 25.1, a)]; 2) que no haya constituido el depósito obligatorio en el Banco de España [art. $25.1, b)]$ y 3) que no haya cumplido las medidas propuestas por la comisión de expertos (art. 25.2). En esta eventual situación de múltiples incumplimientos, prevé la Ley Orgánica que «el Gobierno, con la aprobación por mayoría absoluta del Senado, adoptará las medidas necesarias para obligar a la Comunidad Autónoma a su ejecución forzosa. Para la ejecución de las medidas el Gobierno podrá dar instrucciones a todas las autoridades de la Comunidad Autónoma».

Finalmente, en el caso en que el incumplimiento persista sin que la Comunidad Autónoma o la Administración Local adopten las medidas necesarias, podrá «considerarse como gestión gravemente dañosa para los intereses generales, y podrá procederse a la disolución de los órganos de la Corporación Local incumplidora, de conformidad con lo previsto en el artículo 61 de la Ley 7/1985, de 2 de abril, Reguladora de las Bases de Régimen Local».

Tras analizar el cumplimiento del principio de Estabilidad Presupuestaria y sostenibilidad financiera, parece claro que «la extensión e intensificación de la normativa relativa a la estabilidad presupuestaria ha provocado una apreciable merma del margen para adoptar una política presupuestaria propia» ${ }^{67}$.

La construcción jurídica de las medidas coercitivas y de cumplimiento forzoso, que afectan a la autonomía financiera de las Comunidades Autónomas, han sido definidas como «una nueva manifestación de esa función tuteladora que desnaturaliza la idea de autonomía financiera es la posibilidad de enviar una Comisión que puede llegar a formular propuestas de medidas que serán de obligado cumplimiento para la administración incumplidora» ${ }^{68}$.

Acerca del problema del tipo y el modo de ejercicio del control del cumplimiento de las obligaciones previstas en la Constitución y desarrolladas por la Ley Orgánica 2/2012, se defiende que «la situación de incertidumbre se agrava dado que la revisión del equilibrio presupuestario se ha entendido por la Ley Orgánica, cerrando los espacios abiertos de la Constitución, como un control político o intervención federal y no como un control jurídico ante una autoridad independiente» ${ }^{69}$, justificando, de esta manera, una importante

\footnotetext{
64 ARIAS ABELLÁN, M. D., "Estabilidad presupuestaria y deuda pública: su aplicación a las Comunidades Autónomas”, op. cit., 163.

65 GUERRERO VÁZQUEZ, P., "Freno al endeudamiento autonómico y coerción estatal en la ley orgánica de estabilidad presupuestaria y sostenibilidad financiera", en Revista General de Derecho Constitucional, núm. 23, 2016,1 y ss. 35.

66 MEDINA GUERRERO, M., "El Estado autonómico en tiempos de disciplina fiscal”, op. cit., 142.

67 CARRASCO DURÁN, M., "Estabilidad presupuestaria y Comunidades Autónomas", op. cit., 198.

68 ESCRIBANO LÓPEZ, F., "La autonomía financiera de las comunidades autónomas: crisis económica, estabilidad presupuestaria y sostenibilidad financiera", en Revista española de derecho financiero, núm. 156, 2012, 11 y ss., 19.

69 GARCÍA ROCA, J., "El principio de estabilidad presupuestaria y la consagración del freno al endeudamiento", op. cit., 86.
} 
discrecionalidad del Estado al evaluar, unilateralmente, si las Comunidades Autónomas han cumplido o deben imponerse, por el Estado, medidas correctivas o coercitivas, para garantizar el cumplimiento por las CC.AA. Es evidente que el control de una autoridad independiente se habría configurado como una fuerte garantía de la autonomía financiera de las Comunidades Autónomas.

En tono crítico sobre la regulación jurídica llevada a cabo por la LOEPSF, se afirma que «la LOEPSF, sin embargo, sí ha ido sensiblemente más allá del marco normativo y jurisprudencial precedente porque refuerza significativamente las potestades del Estado sobre las CCAA en materia financiera y presupuestaria y altera el marco normativo de la distribución territorial del poder configurado en las últimas décadas al amparo del principio de autonomía financiera. La norma otorga una clara posición de preeminencia al Ministerio de Hacienda y Administraciones Públicas en el reparto del nivel de déficit y deuda en el que pueden incurrir las diferentes Administraciones Públicas» ${ }^{70}$.

Uno de los efectos más contundentes de la nueva regulación es que los límites presupuestarios no son inherentes exclusivamente a la gestión presupuestaria autonómica; de hecho, afectan igualmente a las políticas desarrolladas por parte de las Comunidades Autónomas. No se puede olvidar el mayor poder que la nueva disciplina presupuestaria ha concedido al Ministerio de Hacienda; el Gobierno central podrá "condicionar la ejecución presupuestaria de las Comunidades Autónomas, ya que la determinación de objetivos de déficit y deuda muy exigentes, y lo son los que tienen planteados las Comunidades Autónomas supondrá colocar sobre las Comunidades Autónomas de forma permanente la espada de Damocles de las medidas preventivas, coercitivas y correctivas previstas en la Ley Orgánica $2 / 2012 »^{71}$.

La Ley Orgánica habilita el Gobierno, con base en el artículo 155 de la Constitución, a la adopción de las medidas necesarias para obligar a su cumplimiento forzoso que podrían llegar incluso, a la «adopción de las medidas necesarias para obligar a su cumplimiento forzoso (art. 26), que podrían llegar incluso, previo requerimiento, a la intervención / suspensión de la Autonomía o a la disolución de la Corporación local. Una norma verdaderamente importante, dura (insólita en lo que ha sido nuestra práctica constitucional del Estado de las Autonomías) pero que, a mi modo de ver, es la clave de arco del mandato constitucional, cuya aplicación requerirá, sin duda, notables dosis de firmeza y prudencia» ${ }^{72}$.

Completando el análisis sobre los instrumentos que afectan a la autonomía financiera de las Comunidades Autónomas, conectados a la LOEPSF, no se puede olvidar el Real Decreto Ley $21 / 2012^{73}$, con el cual se ha reforzado el marco unitario de la Administración del Estado, siendo requerida la autorización central para realizar operaciones instrumentadas en valores y operaciones de crédito en el extranjero. De igual manera, todas las operaciones de crédito de las Comunidades Autónomas, tanto a corto como a largo plazo, deberán ser comunicadas a la Secretaría General del Tesoro y Política Financiera. El artículo 9 del Decreto Ley, además, establece la creación de un "Fondo de liquidez autonómico», con naturaleza de fondo sin personalidad jurídica y con el objetivo de sostener la financiación de las Comunidades Autónomas, previo acuerdo con el Instituto de Crédito Oficial, el ente estatal de gestión del FLA. EI FLA, de hecho, «se configura en forma de crédito estatal a las Comunidades Autónomas para proporcionarles liquidez para financiar su deuda, a cambio de cumplir con una serie de condiciones financieras y fiscales, destinadas básicamente a asegurar el cumplimiento de los objetivos de déficit y deuda, así como el reembolso de las cantidades aportadas por el FLA, bajo la supervisión y el control del Gobierno estatal» ${ }^{74}$.

\section{LA JURISPRUDENCIA DEL TRIBUNAL CONSTITUCIONAL SOBRE EL PRINCIPIO DE ESTABILIDAD PRESUPUESTARIA}

La jurisprudencia del Tribunal Constitucional español (en adelante, TC) sobre el principio de Estabilidad Presupuestaria, anterior a la reforma constitucional del 2011, se desarrolló, sobre todo, desde la perspectiva

70 GUERRERO VÁZQUEZ, P., "Freno al endeudamiento autonómico y coerción estatal en la ley orgánica de estabilidad presupuestaria y sostenibilidad financiera", op. cit., 3-4.

71 CARRASCO DURÁN, M., "Estabilidad presupuestaria y Comunidades Autónomas", op. cit., 200-201.

72 RODRÍGUEZ BEREIJO, A., "La reforma constitucional del artículo 135 CE y la crisis financiera del Estado", op. cit., 29.

73 Real Decreto Ley 21/2012, de 13 de julio, de Medidas de liquidez de las Administraciones Públicas y en el ámbito financiero (BOE núm. 168, de 14-07-2012).

${ }_{74}$ ALBERTI ROVIRA, E., "El impacto de la crisis financiera en el Estado autonómico español", en Revista Española de Derecho Constitucional, núm. 98, mayo-agosto, 2013, 63 y ss., 79. 
de la evaluación de la existencia de la competencia constitucional, a favor del Estado, para establecer parámetros presupuestarios vinculantes para todas las Comunidades Autónomas ${ }^{75}$.

EI TC se pronunció, sobre la relación del principio de Estabilidad Presupuestaria y la autonomía financiera de las Comunidades Autónomas, de manera significativa, en la Sentencia 134/201176. El recurso de inconstitucionalidad, promovido por el Parlamento de Cataluña y desestimado en su totalidad por el TC, se interpuso frente a diversos preceptos de la Ley 18/2001 y de la Ley Orgánica 5/200177. En realidad, como se ha destacado en relación al recurso, «las dudas de inconstitucionalidad se centraban en esencia en la posible extralimitación competencial cometida por el legislador estatal, señaladamente por haber ido más allá de lo previsto en la normativa europea al imponer el déficit cero, así como en la posible vulneración de la autonomía financiera ${ }^{78}$.

EI TC reconoce que todas las disposiciones que transponen, incluso de una forma indirecta, una regulación ya establecida por el Derecho supranacional, no pueden ser declaradas inconstitucionales, en cuanto todos los Estados miembros, al formar parte de la Unión Europea, aceptan limitaciones de soberanía, incluidas las relativas a la disciplina presupuestaria interna. La única manera para declarar inconstitucional una norma sería la de demostrar, efectivamente, la violación de una competencia autonómica expresa.

Además, sobre la cuestión de la competencia del Estado para la definición del concepto de Estabilidad Presupuestaria, el TC afirmó que «la concepción de la Estabilidad Presupuestaria en términos de equilibrio o superávit que tiene el precepto impugnado se aviene con las competencias del Estado previstas en el art. 149.1.13 y 14 CE, competencias que se ejercen en el marco multilateral de coordinación y cooperación previsto por el legislador orgánico» ${ }^{79}$.

EI TC, de la misma manera, desestimó la cuestión de inconstitucionalidad, sobre la Ley 18/2011, relativamente al tema de la aplicación a las Entidades Locales del principio de Estabilidad Presupuestaria. El Tribunal impone un ulterior límite a la autonomía financiera autonómica, especificando que deben considerarse legítimos los controles de legalidad por parte del Estado, a condición de que no sean controles genéricos y que se planteen sobre específicas razones de defensa de la distribución constitucional de las competencias ${ }^{80}$. El TC desestimó los motivos del recurso basándose en dos consideraciones. En primer lugar, el artículo 149.1.13 CE regula la facultad del Estado de establecer reglas generales sobre los presupuestos locales, junto al principio de «coordinación», previsto por el artículo 156.1 de la Constitución.

Dicha disposición constitucional (art. 149.1.13), que atribuye la competencia al Estado sobre las «bases y coordinación de la planificación general de la actividad económica», ha sido ya interpretada, por parte del TC, como «una competencia de dirección general de la economía que se proyecta en los diversos sectores de la misma y también en materia presupuestaria» ${ }^{81}$.

75 Sobre el tema de la constitucionalidad de la Ley 18/2001, General de Estabilidad Presupuestaria, véase COSTA CAMPI, M. T., "Sobre la Ley General de Estabilidad Presupuestaria", en Revista española de control externo, núm. 10, 2002, 15 y ss.

76 STC 134/2011, de 20 de julio de 2011 (BOE núm. 197, de 17-08-2011). Véanse al respecto los siguientes comentarios: URíA FERNÁNDEZ, F., "Una sentencia oportuna e imprescindible. Comentario a la sentencia 134/2011, de 20 de julio, del Tribunal Constitucional, sobre determinados preceptos de las leyes de estabilidad presupuestaria", en García de ENTERRÍA MARTÍNEZ-CARANDE, E. - ALONSO GARCÍA, R. (coords.), Administración y justicia un análisis jurisprudencial, Madrid, 2012, 373 y ss.; además, sobre la Sentencia 134/2011 y la siguiente 157/2011 véanse RUIZ TARRÍAS, S., "De la discusión sobre un «título competencial» a la afirmación de un "mandato constitucional»", en Revista Española de Derecho Constitucional, núm. 100, enero-abril, 2014, 331 y ss. y DE MIGUEL CANUTO, E., "Constitucionalidad de la estabilidad presupuestaria: fundamentos", en Crónica tributaria, núm. extr. 2, 2012, 43 y ss.

77 Las disposiciones impugnadas se referían a la definición del principio de Estabilidad Presupuestaria, a la obligación de las Entidades Locales de ajustar el presupuesto para dar cumplimiento al principio de Estabilidad Presupuestaria, a la atribución de competencia para la elaboración del plan económico-financiero al Ministerio de Hacienda para la corrección del desequilibrio, a la aplicación a las Entidades Locales del principio de Estabilidad Presupuestaria para obtener la autorización para la emisión de deuda y a la disciplina de la corrección de las situaciones de desequilibrio del presupuesto de las Comunidades Autónomas.

${ }^{78}$ MEDINA GUERRERO, M., "La reforma del artículo 135 CE", en Teoría y Realidad Constitucional, núm. 29, 2012, 131 y ss., 139.

79 STC 134/2011, Fundamentos Jurídicos, p.to 8.

80 La consolidada jurisprudencia del TC ha establecido, desde la Sentencia 4/1981 (STC 4/1981, de 2 de febrero de 1981, BOE núm. 47, de 24-02-1981, Fundamentos Jurídicos, p.to 3), que «el principio de autonomía es compatible con la existencia de un control de legalidad sobre el ejercicio de las competencias, si bien entendemos que no se ajusta a tal principio la previsión de controles genéricos e indeterminados que sitúen a las entidades locales en una posición de subordinación o dependencia cuasi jerárquica de la Administración del Estado u otras Entidades territoriales. En todo caso, los controles de carácter puntual habrán de referirse normalmente a supuestos en que el ejercicio de las competencias de la entidad local incida en intereses generales concurrentes con los propios de la entidad, sean del Municipio, la Provincia, la Comunidad Autónoma o el Estado».

${ }^{81}$ STC 134/2011, Fundamentos Jurídicos, p.to 7. Véase, además, como antecedente jurisprudencial sobre este tema, entre otras, la Sentencia 197/1996, de 28 de noviembre de 1996 (BOE núm. 3, Suplemento, de 03-01-1997), especialmente el p.to 4 de los Fundamentos Jurídicos. 
En segundo lugar, afirma el TC, que no hay violación de las atribuciones constitucionales de las Entidades Locales porque la disciplina que estamos analizando no afecta a su autonomía, en cuanto no es inconstitucional una regulación normativa que prevea la necesaria obtención de una autorización estatal para todas las operaciones de crédito y emisión de deuda (en una situación de desequilibrio presupuestario), por parte de las Entidades Locales, con el claro objetivo de limitar su capacidad de endeudamiento (Fundamentos Jurídicos, p.to $14 b)^{82}$.

El TC, de hecho, considerando constitucionalmente legítimas las competencias del Consejo de Política Fiscal y Financiera, afirmó que «la apreciación por el Consejo de Política Fiscal y Financiera de las Comunidades Autónomas de si el plan económico-financiero elaborado por éstas se adecua o no al objetivo de Estabilidad Presupuestaria se detiene allí, esto es, no conlleva en el caso de que la apreciación sea negativa la sustitución en la competencia de la Comunidad Autónoma para la elaboración del plan, sustitución que sería inconstitucional ${ }^{83}$, sino que se traduce en un requerimiento a aquélla para que lleve a cabo su reformulación ${ }^{84}$. En dicha Sentencia, el TC reproduce la que ha sido su consolidada jurisprudencia en materia de política económica general del Estado, afirmando la competencia estatal para establecer previsiones generales comunes para poner freno al endeudamiento general, causado por el Estado mismo y por los niveles intermedios de Gobierno ${ }^{85}$.

En este contexto debe destacarse, al margen de esta Sentencia del TC, el razonamiento del Tribunal, al desestimar las cuestiones de inconstitucionalidad planteadas por parte de la Generalitat de Cataluña, el cual para justificar su decisión «recoge la doctrina anterior, de forma ordenada, y afirma no sólo la legitimidad de que el Estado establezca criterios de estabilidad presupuestaria más estrictos que los contenidos en el Derecho de la Unión Europea, sino también la propia justificación de la estabilidad presupuestaria, y la posibilidad de imposición unilateral a los entes subcentrales» ${ }^{86}$.

Finalmente, ha de resaltarse, a diferencia de la posterior Sentencia 215/2015 relativa a la Ley Orgánica 2/2012, que el TC «se pronunció sobre un sistema de Estabilidad Presupuestaria que carecía de un verdadero instrumento sancionador interno y adolecía de una débil previsión sobre la posibilidad de repercutir sobre los entes infractores las eventuales sanciones impuestas por Bruselas. Un sistema, en fin, de más que dudosa eficacia, como lo acreditan los numerosos incumplimientos cometidos por las $\mathrm{CCAA} »^{87}$.

La Sentencia 157/2011 ${ }^{88}$ completó el contenido de la doctrina del TC sobre el principio de Estabilidad Presupuestaria y el reparto de competencias entre el Estado y las Comunidades Autónomas en materia de presupuesto, gasto y gestión financiera del Estado en su conjunto.

El recurso, promovido por el Consejo de Gobierno del Principado de Asturias y desestimado por el TC, impugnaba la constitucionalidad de algunos artículos de la Ley 18/2001, General de Estabilidad Presupuestaria ${ }^{89}$. Siguiendo la clásica postura jurisprudencial, confirmada, en particular, por la citada Sentencia 134/2011, el TC afirma que la noción de Estabilidad Presupuestaria se plantea en el marco de la orientación de la política económica general que el Estado puede dictar, con base en el artículo 149.1.13 de la Constitución española. Además, de conformidad con las Sentencias 62/200190 y 134/2011, el TC sostiene la legiti-

82 Véase, en particular, la consolidada jurisprudencia del TC sobre la facultad estatal de limitar la capacidad de endeudamiento de las Entidades Locales (entre otras, Sentencias 4/1981, 57/1983 y 233/1999).

${ }^{83}$ Entre todas, se vea como precedente jurisprudencial la Sentencia 118/1986, de 27 de junio de 1986 (BOE núm. 276, de 18-111986), especialmente el p.to 18 de los Fundamentos Jurídicos.

${ }_{84}$ STC 134/2011, Fundamentos Jurídicos, p.to 11

85 Sobre la jurisprudencia del TC en materia de límites al ejercicio de las competencias en materia económica que pueden afectar al ejercicio de la potestad presupuestaria, véase ESCRIBANO LÓPEZ, F., "La autonomía financiera de las comunidades autónomas: crisis económica, estabilidad presupuestaria y sostenibilidad financiera", en Revista española de derecho financiero, núm. 156, 2012,11 y ss.; asimismo, CARRASCO DURÁN, M., El reparto de competencias entre el Estado y las Comunidades Autónomas sobre la actividad económica, Valencia, 2005.

${ }^{86}$ RUIZ ALMENDRAL, V., "La reforma Constitucional a la luz de la estabilidad presupuestaria", en Cuadernos de Derecho Público, núm. 38, septiembre-diciembre, 2009, 89 y ss., 111.

87 MEDINA GUERRERO, M., "La reforma del artículo 135 CE", op. cit., 144-145.

${ }_{88}$ STC 157/2011, de 18 de octubre de 2011 (BOE núm. 275, de 15-11-2011).

89 Las disposiciones impugnadas por el Consejo de Gobierno del Principado de Asturias se referían, específicamente, a la definición de Estabilidad Presupuestaria, a la obligación de los sujetos comprendidos en el ámbito de aplicación de establecer normas reguladoras en materia presupuestaria y los instrumentos y procedimientos necesarios para adecuarlas al objetivo de cumplimiento del principio de estabilidad presupuestaria y la obligación de formular un plan económico y financiero de saneamiento de una situación excepcional de déficit presupuestario.

90 STC 62/2001, de 1 de marzo de 2001 (BOE núm. 77, Suplemento, de 30-03-2001). 
midad del establecimiento de límites prácticos en el ámbito presupuestario de las Comunidades Autónomas y las Entidades Locales.

En efecto, el TC ha utilizado diferentes criterios en relación a la interpretación de la competencia sobre las «bases y coordinación de la planificación de la actividad económica», ex artículo 149.1.13, atendiendo a la «apreciación casuística de su incidencia en la economía, en el logro de objetivos de la política económica general, de la unidad económica o de otros principios y objetivos de índole análoga» ${ }^{91}$. Mediante, también, la Sentencia $186 / 2011^{92}$ el TC ha totalmente confirmado su precedente postura jurisprudencial en el ámbito de aplicación del principio de Estabilidad Presupuestaria a las CC.AA. ${ }^{93}$.

En definitiva, como se ha observado claramente en el ámbito de la jurisprudencia del TC sobre el principio de Estabilidad Presupuestaria anterior a la reforma del artículo 135 de la Constitución, todos los pronunciamientos han desestimado los recursos de inconstitucionalidad contra las leyes que establecían la necesidad de respectar, por el Estado, las Comunidades Autónomas y las Entidades Locales, el principio de Estabilidad Presupuestaria.

La Sentencia 215/2014 ${ }^{94}$ del TC constituye la primera decisión del TC sobre el principio de Estabilidad Presupuestaria, posteriormente a su constitucionalización, a través del reformado artículo 135 y su desarrollo normativo mediante la L. O. 2/2012. El juicio de constitucionalidad, de hecho, se planteó ante el TC, mediante un recurso interpuesto por el Gobierno de Canarias, en relación con numerosas disposiciones contenidas en la Ley Orgánica 2/2012 de Estabilidad Presupuestaria y Sostenibilidad Financiera ${ }^{95}$.

EI TC, desestimando todos los motivos de inconstitucionalidad ${ }^{96}$, declaró, al comenzar de su pronunciamiento, que «desde la entrada de España en la Comunidad Económica Europea mediante el Acta de adhesión de 12 de junio de 1985, la Estabilidad Presupuestaria se ha erigido en un instrumento imprescindible para lograr la consolidación fiscal de los Estados miembros» ${ }^{97}$.

Uno de los aspectos más criticados de la LOEPSF, por parte del Gobierno de Canarias, es el artículo 19 de la L. O. 2/2012, cuando se refiere a la «advertencia de riesgo de incumplimiento». El recurrente alegaba que dichas disposiciones vulneraban por un lado el principio de lealtad constitucional entre el Estado y las Comunidades Autónomas y, por otro lado, el principio de reserva de ley del artículo 135 de la Constitución, puesto que el riesgo de incumplimiento del objetivo de Estabilidad Presupuestaria convertía en un riesgo excesivamente indeterminado, que podría ser utilizado arbitrariamente, por parte del Gobierno.

91 STC 186/1988, de 17 de octubre de 1988 (BOE núm. 267, Suplemento, del 07-11-1988). Para profundizar el estudio sobre la competencia en materia de actividad económica, con particular referencia al artículo 149.1.13 CE, véase, por todos, CARRASCO DURÁN, M., "El reparto de competencias entre el Estado y las Comunidades Autónomas sobre la actividad económica", op. cit., espec. 179 y ss.

92 STC 186/2011, de 23 de noviembre de 2011 (BOE núm. 306, de 21-12-2011).

${ }_{93}$ Las disposiciones impugnadas se referían, en particular, a la aplicación a las Comunidades Autónomas de los mismos principios generales de la Ley 18/2001, la regulación de la corrección de las situaciones de desequilibrio, la obligación para las Comunidades Autónomas de pedir autorización al Estado para efectuar operaciones de crédito en el extranjero y para la emisión de deuda u otra modalidad de crédito público y la configuración del Consejo de Política Fiscal y Financiera de las Comunidades Autónomas, como órgano de coordinación entre el Estado y las Comunidades Autónomas en materia fiscal y financiera, atribuyéndole competencias, especialmente, en el ámbito de la coordinación de la política presupuestaria del Estado y las Comunidades Autónomas (estudio, elaboración y revisión de los métodos utilizados para el cálculo de los costes de los servicios transferidos a las Comunidades Autónomas, la coordinación en la política de endeudamiento y, en general, todos los aspectos de la actividad financiera de las Comunidades Autónomas).

94 STC 215/2014, de 18 de diciembre de 2014 (BOE núm. 29, de 03-02-2015). Véanse, en particular, el comentario crítico de ARROYO GIL, A., "Estabilidad presupuestaria y autonomía territorial", en TUDELA, J. - KÖLLING, M. (coords.), Costes y Beneficios de la descentralización política en un contexto de crisis: El caso español, Zaragoza, 2015, 13 y ss. y, además, GARCíA ROCA, J. MARTíNEZ LAGO, M. A., "La repentina constitucionalidad de la Ley de estabilidad presupuestaria según la STC 215/2014, de 18 de diciembre", en Civitas. Revista española de derecho europeo, núm. 54, 2015, 89 y ss.

${ }_{95}$ En particular, el recurso del Gobierno de Canarias se refería al establecimiento, por parte del Estado, de mecanismos de coordinación entre todas las Administraciones Públicas para garantizar el cumplimiento de las previsiones de la reforma constitucional del artículo 135 y de la LOEPSF, a la aplicación de los parámetros establecidos por la Comisión europea para el cálculo del déficit estructural, a la determinación unilateral, por parte del Estado, de los objetivos de Estabilidad Presupuestaria y deuda pública para cada una de las Comunidades Autónomas, a la necesidad de informe favorable por parte del Ministerio de Hacienda y Administraciones Públicas para la concesión de subvenciones a las Comunidades Autónomas que no hayan cumplido los objetivos de Estabilidad Presupuestaria, deuda pública o regla del gasto, al envío por parte del Gobierno de una comisión de expertos para evaluar la situación económica y financiera de la Comunidad Autónoma o Administración Pública que no haya cumplido los objetivos de Estabilidad Presupuestaria, a la regulación de las medidas de cumplimiento forzoso, a la responsabilidad autonómica por incumplimiento de normas de Derecho comunitario, de competencia interior autonómica.

${ }_{96}$ No obstante, cinco Magistrados discreparon en un voto Particular.

97 STC 215/2014, Fundamentos Jurídicos, p.to 2. 
Asimismo, con referencia al citado artículo 19 de la Ley Orgánica 2/2012, el recurrente afirmaba que resultaba lesionado también el principio de autonomía consagrado en el artículo 137 de la Constitución española, en cuanto el «riesgo» de incumplimiento, a juicio del Gobierno de Canarias, adquiría un carácter demasiado indeterminado, pudiendo dar lugar a las mismas consecuencias ocasionadas por un efectivo incumplimiento del objetivo de Estabilidad Presupuestaria, siendo éste, también, un efecto irracional de la norma.

Frente a estas consideraciones, el TC afirma que «tanto el cumplimiento de los objetivos por parte de cada Administración pública como la labor de verificación del mismo deberá efectuarse de acuerdo con los objetivos de déficit y endeudamiento fijados para cada ejercicio (...) Estamos en presencia de unas medidas que, aun afectando al ámbito de autonomía de las Comunidades Autónomas, deben considerarse legítimas desde el punto de vista constitucional por dirigirse a la corrección de la desviación producida en orden a permitir tanto el cumplimiento de los objetivos individualmente marcados, como la acción homogénea de todos los entes implicados de cara a la consecución del objetivo colectivamente asumido» ${ }^{98}$.

Como ha afirmado parte de la doctrina, «resulta muy dudoso que en el ejercicio de sus competencias para la dirección general de la actividad económica el Estado pueda proponer las medidas necesarias para lograr la corrección de la desviación existente porque ello sea además acorde con la previsión del artículo 135.5 a) CE, ya que este precepto únicamente atribuye a la ley orgánica la regulación de "la distribución de los límites de déficit y de deuda entre las Administraciones Públicas, los supuestos excepcionales de superación de los mismos y la forma y plazo de corrección de las desviaciones que sobre uno y otro pudieran producirse". Me parece, en efecto, que de ahí no cabe derivar la posibilidad de que tal ley orgánica habilite en blanco al Estado para la consecución de tal objetivo por los medios que el mismo decida» ${ }^{99}$.

EI TC, sin embargo, no atendió esta reclamación, declarando además que «no cabe duda, entonces, de que la Ley Orgánica 2/2012 ha dado debido cumplimiento al mandato previsto en el art. 135.5 CE, que exige la regulación por ley orgánica de la "participación, en los procedimientos respectivos, de los órganos de coordinación institucional entre las Administraciones Públicas en materia de política fiscal y financiera", sin que la suficiencia o insuficiencia de la participación del Consejo de Política Fiscal y Financiera, desde esta perspectiva, pueda analizarse, como hace el Gobierno de Canarias, de forma aislada, en cada una de las fases del procedimiento dirigido a corregir las desviaciones en el cumplimiento de los objetivos de Estabilidad Presupuestaria, de deuda pública o de la regla de gasto» ${ }^{100}$. En particular, sobre la cuestión de la evaluación de los efectos de la reforma constitucional, el TC declara que «con carácter específico, a las Comunidades Autónomas, se les impone la obligación de adoptar las "disposiciones" y "decisiones presupuestarias" necesarias "para la aplicación efectiva del principio de estabilidad" (art. 135.6 CE). De esta manera, la redacción dada al art. 135 CE consagra unos nuevos límites a la autonomía financiera de las Comunidades Autónomas que condicionan sus políticas de gasto al someterlas no sólo a las políticas que, en materia de Estabilidad Presupuestaria, determine con carácter general el Estado, sino ahora también a las que adopten las propias instituciones europeas» ${ }^{101}$. En relación a esta última afirmación del TC, parte de la doctrina habla de «una interpretación que añade oscuridad al ya de por sí complejo diseño legal de medidas correctivas y coercitivas» ${ }^{102}$. Aquí se plantea nuevamente el tema central en toda la discusión sobre la Estabilidad Presupuestaria: la relación entre la Unión Europea y los Estados miembros y cómo esta relación afecta a la división competencial interna entre el Estados y las Comunidades Autónomas ${ }^{103}$. En virtud de la LOEPSF el

98 STC 215/2014, Fundamentos Jurídicos, p.to 4.

99 ARROYO GIL, A., "Estabilidad presupuestaria y autonomía territorial", op. cit., 34

100 STC 215/2014, Fundamentos Jurídicos, p.to 6.

101 STC 215/2014, Fundamentos Jurídicos, p.to 7. En sentido contrario, la opinión minoritaria de TC plantea, en relación a la incidencia de las medidas coercitivas en la autonomía financiera de las Comunidades Autónomas, una diferente cuestión substancial. De hecho, se afirma que «una cosa es imponer a la Comunidad Autónoma la elaboración de un plan o la comprobación de su idoneidad para alcanzar los objetivos de estabilidad, y otra, bien diferente, sustituir la competencia autonómica para adoptar sus propias políticas mediante la elaboración por el Estado del referido plan. La atribución a la comisión de expertos de autoridad para proponer medidas de cumplimiento obligatorio no sería sino una indebida sustitución de la competencia de una Comunidad Autónoma para adoptar sus propias políticas públicas, políticas que ciertamente deben respetar el objetivo de Estabilidad Presupuestaria» (p.to 2 Voto particular).

102 GUERRERO VÁZQUEZ, P., "Freno al endeudamiento autonómico y coerción estatal en la ley orgánica de estabilidad presupuestaria y sostenibilidad financiera", op. cit., 35.

${ }_{103}$ Los Estados son responsables del cumplimento de las obligaciones asumidas en ámbito europeo, aunque estas obligaciones no sean concordadas en el espacio jurídico interior al Estado. En esta manera, efectivamente, las CC.AA. reciben directivas del Estado que, a su vez, le recibió por las Instituciones supranacionales. En este sentido véase, como ejemplo paradigmático, cuanto establecido por el Reglamento UE 473/2013 del Parlamento Europeo y del Consejo, de 21 de mayo de 2013, sobre disposiciones comunes para 
Estado supervisa los presupuestos autonómicos. Es necesario recordar que la Comisión supervisará la evolución de la situación presupuestaria de cada Estado miembro y de sus niveles de endeudamiento público, de conformidad con el artículo 126, apartado segundo, del Tratado de Funcionamiento de la Unión Europea.

Es el propio TC el que, confirmando la desestimación del recurso contra la LOEPSF, debido a los argumentos señalados, sostiene que «son los Gobiernos de los Estados miembros de la Unión Europea los que tienen la obligación de evitar "Ios déficits excesivos" (art. 126.1 TFUE) y los que asumen la obligación de asegurar el cumplimiento de las obligaciones derivadas del Derecho de la Unión (art. 4.3 TUE), siendo los únicos responsables "de los déficits del gobierno general"» ${ }^{104}$.

\section{CONCLUSIONES}

Abordando el tema de la incidencia del principio de Estabilidad Presupuestaria en la autonomía financiera de las Comunidades Autónomas, es necesario subrayar, en primer lugar, las dificultades concernientes al nuevo enfoque del derecho público en el tema en cuestión ${ }^{105}$.

Las modificaciones del marco estructural, la relación continúa entre temas «clásicos» ${ }^{106}$ del constitucionalismo contemporáneo, con conceptos al mismo ajenos ${ }^{107}$, ha producido la necesidad de desarrollar un análisis que tenga en cuenta, simultáneamente, la relación entre las dos categorías ${ }^{108}$.

En segundo lugar, debe adherirse a la tesis, que ve de acuerdo a la mayoría de la doctrina constitucionalista italiana y española, por la cual la introducción de la «regla de oro» en las Constituciones nacionales sea la consecuencia de las tensiones en los mercados financieros, provocada por la presión especulativa sobre los títulos de la deuda soberana ${ }^{109}$.

Además, reformas constitucionales que afecten tan profundamente el concepto de "Constitución económica y financiera» ${ }^{110}$, delineando nuevos paradigmas y reglas jurídicas, no tendrían que ser consecuencia de las tensiones en los mercados financieros que, de hecho, ellos mismos determinan estímulos y reacciones previsibles por parte de los Estados.

De hecho, el estudio conecta necesariamente el nivel europeo (o, en el caso de los mercados financieros, global) y el nivel nacional, con la consecuencia en que, mediante la introducción de la «regla de oro», se produce la translación en el ordenamiento interno de parámetros económicos externos a la dimensión nacional.

Los Estados ( $y$, específicamente, los Gobiernos), de hecho, tienen que legitimarse no solo frente a los ciudadanos, sino también frente a los mercados internacionales.

el seguimiento y la evaluación de los proyectos de planes presupuestarios y para la corrección del déficit excesivo de los Estados miembros de la zona del euro, donde se establece que los Estados miembros de la zona euro deben consultarse con las Instituciones europeas para introducir, a nivel nacional, modificaciones sobre composición y disciplina jurídica de los presupuestos.

104 STC 215/2014, Fundamentos Jurídicos, p.to 9

105 Sobre el nuevo enfoque del derecho público véase, por todos, BILANCIA, F., "Spending review e pareggio di bilancio. Cosa rimane dell'autonomia locale?", en Diritto Pubblico, 1/2014, 45 y ss. y MANGIAMELI, S., "Crisi economica e distribuzione territoriale del potere politico (relazione introduttiva al XXVIII Convegno annuale dell'Associazione italiana dei costituzionalisti)", en Rivista AIC, 4, 2014, espec. 1-19.

106 En particular, conceptos como soberanía, Constitución, Autonomía local, relación entre Gobierno y Parlamento.

107 Como, por ejemplo, spending review, subprime, Fiscal compact, Estabilidad Presupuestaria, crisis de la deuda soberana, sostenibilidad financiera, etc.

108 Véase, entre todos, BILANCIA, F., "Juridification, società civile e identità nazionale nel processo di integrazione europea", en Diritto Pubblico, 3/2016, 937 y ss.

109 En este sentido BILANCIA, F., "Note critiche sul c.d. pareggio di bilancio", en Rivista AIC, 2/2012, espec. 2 y ss.; BRANCASI, A., "L'introduzione del principio del c.d. pareggio di bilancio: un esempio di revisione affrettata della Costituzione", en Forumcostituzionale.it, espec. 4 y ss.; GRASSO, G., Il costituzionalismo della crisi, Napoli, 2012, espec. 93 y ss.; CARMONA CONTRERAS, A. M., "Costituzionalizzazione del principio del pareggio di bilancio e limiti alla sovranità statale: l'esperienza della riforma costituzionale in Spagna", op. cit., espec. 245 y ss.; MEDINA GUERRERO, M., "La constitucionalización de la regla del equilibrio presupuestario: integración europea, centralización estatal”, en Revista de Estudios Políticos (nueva época), núm. 165, julio-septiembre, 2014 , 189 y ss.; GARCÍA-ESCUDERO MÁRQUEZ, P., "La acelerada tramitación parlamentaria de la reforma del artículo 135 de la Constitución”, op. cit., espec. 172 y ss.; RIDAURA MARTÍNEZ, M. J., "La reforma del artículo 135 de la Constitución española: ¿pueden los mercados quebrar el consenso constitucional?", op. cit., espec. 249 y ss.; LÓPEZ AGUILAR, F., "De la Constitución «irreformable» a la reforma constitucional «exprés»", op. cit., espec. 208 y ss.

110 Sobre el tema de la evolución de la Constitución económica y financiera, también en óptica comparada, véase, en particular, CASSESE, S. (cur.), La nuova Costituzione economica, Roma-Bari, 2012; DI PLINIO, G., Il common core della deregulation. Dallo Stato regolatore alla Costituzione economica sovranazionale, Milano, 2005; CERRINA FERONI, G. - FERRARI, G. F. (cur.), Crisi economicofinanziaria e intervento dello Stato. Modelli comparati e prospettive, Torino, 2012; SAITTO, F., "«Costituzione finanziaria» ed effettività dei diritti sociali nel passaggio dallo «Stato fiscale» allo "Stato debitore»", en Rivista AIC, 1, 2017, espec. 2 y ss. 
$\mathrm{Y}$, además, el papel desempeñado por parte del TC, anteriormente y posteriormente a la reforma constitucional de 2011, aprobó, de hecho, la progresiva recentralización competencial, justificando las acciones estatales con la necesidad, por un lado, de garantizar la sostenibilidad financiera del Estado (en particular frente a los mercados y a la Unión europea) y, por otro lado, el título competencial contenido en el artículo 149.1.13, que atribuye la competencia al Estado sobre las «bases y coordinación de la planificación general de la actividad económica», ha sido interpretado, por parte del TC, como «una competencia de dirección general de la economía que se proyecta en los diversos sectores de la misma y también en materia presupuestaria».

La STC 215/2014, en particular, se plantea en continuidad con su propia jurisprudencia histórica sobre la regulación estatal en materia de gasto y presupuesto, aunque en este caso autonómico, y que produce una afectación de la autonomía financiera de las Comunidades Autónomas, al ser unilateral la fijación de los límites de gasto y deuda pública, el establecimiento de los objetivos presupuestarios y el análisis del cumplimiento de dichos límites ${ }^{111}$.

Como ha sido afirmado con autoridad, las reformas constitucionales en época de crisis económica y financiera ha sido la «risposta in chiave essenzialmente politica per affrontare un momento assai complicato e piuttosto eccezionale. La revisione costituzionale è stata perseguita, dunque, come segnale chiaro lanciato agli attori che reggono la governance economica europea e a quelli che controllano i mercati finanziari, sottolineando decisamente e senza alcun margine di dubbio che la Spagna prendeva sul serio gli obblighi europei relativi al bilancio e al controllo del deficit e del debito pubblico» ${ }^{112}$.

Las reglas de gasto, de Estabilidad Presupuestaria y de Sostenibilidad Financiera, por otro lado, no pueden considerarse como un fenómeno de forma inesperada, debido únicamente a la crisis económica. De hecho, no se puede olvidar que una considerable afectación de la soberanía estatal, específicamente en tema de reglas presupuestarias, monetarias y financieras, debe ser encontrada en el Tratado de Maastricht ${ }^{113}$. En este ámbito, parte de la doctrina, estudiando el impacto directo del derecho europeo sobre los ordenamientos jurídicos nacionales, ha especificado que «la justificación técnico-jurídica de las excepciones a la operatividad del principio de autonomía institucional o, si se quiere expresar de manera más clara a los efectos concretos de este trabajo, de la recentralización competencial en los ámbitos de la seguridad industrial y del medio ambiente se encuentra en última instancia, y siempre en mi opinión, en el juego del principio de primacía del Derecho europeo. En este caso, en concreto, en la primacía de normas comunitarias sobre preceptos de rango constitucional (las reglas 13. ${ }^{a}$ y 23. ${ }^{a}$ del apartado 1 del art. $149 \mathrm{CE}$ ), en la interpretación hecha de los mismos por nuestro Tribunal Constitucional a la hora de enjuiciar dos normas reglamentarias (el Real Decreto 2140/1985 y el Real Decreto 85/1996), que constituyen una proyección de dichos preceptos constitucionales» ${ }^{114}$.

En relación con la fijación de los objetivos de Estabilidad Presupuestaria y deuda pública, del Estado y de las Comunidades Autónomas, habría sido una ulterior y decisiva garantía de las competencias autonómicas y, en general, de la equilibrada distribución de los objetivos entre todas las Administraciones Públicas que componen el ordenamiento jurídico español, otorgarle un papel relevante, en este ámbito, a la Autoridad Independiente de Responsabilidad Fiscal (AIREF), instituida por la Ley Orgánica 6/2013 115 .

La AIREF ${ }^{116}$ puede elaborar informes, opiniones y estudios sobre la sostenibilidad del presupuesto y del endeudamiento de las Administraciones Públicas. Además, el incumplimiento reiterado del deber de colaboración de las Administraciones Públicas con la Autoridad Independiente de Responsabilidad Fiscal puede (previa audiencia del sujeto incumplidor) llevar aparejada la imposición de las medidas automáticas de corrección ${ }^{117}$.

111 Postura jurisprudencial del TC confirmada, en particular, mediante las recientes Sentencias 18/2016, 31/2016, 101/2016, 93/2017 y 107/2017.

112 CARMONA CONTRERAS, A. M., "Costituzionalizzazione del principio del pareggio di bilancio e limiti alla sovranità statale: l'esperienza della riforma costituzionale in Spagna", op. cit., 239.

113 Para un análisis del concepto de «soberanía» en el ordenamiento jurídico multinivel véase, entre todos, BOSIO, A. - DELLAVALLE, S., "Crisi e ridefinizione della sovranità nel contesto plurilivellare", in Costituzionalismo.it, Fasc. 3, 2016.

114 ÁLVAREZ GARCÍA, V., "La recentralización de competencias en España por imperativo del derecho europeo", op. cit., 31.

115 El artículo 2 de la L. O. 6/2013 atribuye a la Autoridad Independiente de Responsabilidad Fiscal la finalidad de "garantizar el cumplimiento efectivo por las Administraciones Públicas del principio de Estabilidad Presupuestaria (...), mediante la evaluación continua del ciclo presupuestario, del endeudamiento público, y el análisis de las previsiones económicas”.

116 La AIREF es un órgano autónomo e independiente, con naturaleza consultiva, que colabora con la evaluación del cumplimiento de las previsiones del reformado artículo 135 CE y de la LOEPSF.

117 Corresponde al Presidente de la Autoridad Independiente de Responsabilidad Fiscal la apreciación del incumplimiento grave o reiterado. Aclarado el incumplimiento del deber de colaboración, el Presidente de la AIREF lo comunicará al Gobierno español y a las Cortes Generales. 
Sin embargo, el ap.do 5 del art. 4 de la L. O. 6/2013 establece que «las funciones de la Autoridad Independiente de Responsabilidad Fiscal previstas en este artículo se ejercerán sin perjuicio de las que la Ley Orgánica 8/1980, de 22 de septiembre, de financiación de las Comunidades Autónomas reconoce al Consejo de Política Fiscal y Financiera». Aquí, efectivamente, hay un problema competencial y metodológico claro. ¿Quién es el que realmente evalúa y controla la situación de eventual incumplimiento de los objetivos presupuestarios y de endeudamiento público?

Analizando la L. O. 2/2012 parece claro que la fijación de los límites y la evaluación del cumplimiento de los mismos, incluidas la evaluación de los planes económicos-financieros y de reequilibrio de la situación de incumplimiento, es una competencia atribuida al Consejo de Política Fiscal y Financiera. Sin embargo, la introducción de la AIREF añade, en el marco normativo interno otro organismo que puede evaluar el cumplimiento de los objetivos presupuestarios y de endeudamiento público.

Por su condición de Autoridad independiente, prever un papel más relevante, en particular referido a la imposición de los planes de reequilibrio en casos de incumplimiento, habría sido una importante garantía de imparcialidad entre las Administraciones Públicas y, además, una relevante garantía del respecto del principio constitucional de autonomía financiera autonómica.

Por otro lado, el proceso de modificación del régimen presupuestario interno, junto al reforzamiento de las reglas europeas en tema de gasto y sostenibilidad financiera, ha producido, en consecuencia, que «la sovranità dello Stato spagnolo dopo la riforma del 2011 si sia indebolita in modo non certo marginale» ${ }^{118}$.

La autonomía financiera, cerrada entre los estrechos espacios dejados por la regulación constitucional y su posterior desarrollo normativo, deja todavía más central el debate sobre la efectiva, real autonomía, en particular financiera, que queda en la disponibilidad de las Comunidades Autónomas. De esta manera, la crisis económica y financiera ha producido (explícitamente en el caso italiano, implícitamente en el caso español) una progresiva recentralización ${ }^{119}$ de las competencias, de tal manera que el principio de autonomía, local y regional, constitucionalmente garantizado, resulta fuertemente atenuado ${ }^{120}$.

\section{REFERENCIAS BIBLIOGRÁFICAS}

AGUIAR DE LUQUE, L. - ROSADO IGLESIAS, G., "La estabilidad presupuestaria y su eventual proyección en el Estado de las Autonomías", en Cuadernos de Derecho Público, núm. 12, enero-abril, 2001,9 y ss.

ALBERTI ROVIRA, E., "El impacto de la crisis financiera en el Estado autonómico español", en Revista Española de Derecho Constitucional, núm. 98, mayo-agosto, 2013, 63 y ss., 79.

ÁLVAREZ GARCÍA, V., "La recentralización de competencias en España por imperativo del derecho europeo", en Revista General de Derecho Constitucional, núm. 18, 2014.

ARIAS ABELLÁN, M. D., "Estabilidad presupuestaria y deuda pública: su aplicación a las Comunidades Autónomas", en Revista d'Estudis Autonómics i Federales, núm. 18, octubre, 2013, 126 y ss.

ARROYO GIL, A., "Estabilidad presupuestaria y autonomía territorial", en TUDELA, J. - KÖLLING, M. (coords.), Costes y Beneficios de la descentralización política en un contexto de crisis: El caso español, Zaragoza, 2015.

BAR CENDÓN, A., "La reforma constitucional y la gobernanza económica de la Unión europea", en Teoría y Realidad Constitucional, núm. 30, 2012, 59 y ss.

BILANCIA, F., "Juridification, società civile e identità nazionale nel processo di integrazione europea", en Diritto Pubblico, 3, 2016, 937 y ss.

BILANCIA, F., "Spending review e pareggio di bilancio. Cosa rimane dell'autonomia locale?", en Diritto Pubblico, 1, 2014,45 y ss.

BILANCIA, F., "Note critiche sul c.d. pareggio di bilancio", en Rivista AIC, 2, 2012, espec. 2 y ss.

BOSIO, A. - DELLAVALLE, S., "Crisi e ridefinizione della sovranità nel contesto plurilivellare", in Costituzionalismo.it, Fasc. 3, 2016.

BRANCASI, A., "L'introduzione del principio del c.d. pareggio di bilancio: un esempio di revisione affrettata della Costituzione", en Forumcostituzionale.it, espec. 4 y ss.

118 CARMONA CONTRERAS, A. M., "Costituzionalizzazione del principio del pareggio di bilancio e limiti alla sovranità statale: l'esperienza della riforma costituzionale in Spagna", op. cit., 250.

119 Sobre el proceso de recentralización de las competencias en el ordenamiento jurídico italiano se vea, en particular, MANGIAMELI, S., Le Regioni italiane tra crisi globale e neocentralismo, Milano, 2013, espec. 39 y ss.

120 En tema de centralización de las competencias, debido también al impacto del derecho europeo sobre el Estado autonomico español véanse ÁLVAREZ GARCÍA, V., "La recentralización de competencias en España por imperativo del derecho europeo", op. cit., espec. 30 y ss.; URRUTIA LIBARONA, I., "Crisis económica, estabilidad presupuestaria y recentralización de competencias", op. cit., espec. 9 y ss. 
CARMONA CONTRERAS, A. M., "Costituzionalizzazione del principio del pareggio di bilancio e limiti alla sovranità statale: l'esperienza della riforma costituzionale in Spagna", en MARSOCCI, P. (coord.), Partecipazione politica transnazionale, rappresentanza e sovranità nel progetto europeo, Napoli, 2016.

CARRASCO DURÁN, M., "Estabilidad presupuestaria y Comunidades Autónomas", en Revista d'Estudis Autonómics i Federales, núm. 18, octubre, 2013.

CARRILLO, M., "Constitución y control de las finanzas públicas", en Revista Española de Derecho Constitucional, núm. 101, mayo-agosto, 2014.

CARRASCO DURÁN, M., El reparto de competencias entre el Estado y las Comunidades Autónomas sobre la actividad económica, Valencia, 2005.

CASSESE, S. (cur.), La nuova Costituzione economica, Roma-Bari, 2012.

CAZORLA PRIETO, L. M., "Comentario al Artículo 135 de la Constitución española", en GARRIDO FALLA, M. (coord.), Comentarios a la Constitución, Madrid, 1985, 2.054 y ss.

CERRINA FERONI, G. - FERRARI, G. F. (cur.), Crisi economico-finanziaria e intervento dello Stato. Modelli comparati e prospettive, Torino, 2012.

CLOSA MONTERO, C., "Los cambios institucionales en la gobernanza macroeconómica y fiscal de la UE: hacia una mutación constitucional europea", en Revista de Estudios Políticos (nueva época), núm. 165, julio-septiembre, 2014, 65 y ss.

COSIMO, E. D., "En búsqueda de la soberanía perdida. El principio del equilibrio presupuestario entre la coordinación constitucional y la reforma de la gobernanza económica de la unión europea”, en ÁLVAREZ CONDE, E. - SOUTO GALVÁN, C. (coords.), La constitucionalización de la estabilidad presupuestaria, Madrid, 2012, 85 y ss.

COSTA CAMPI, M. T., "Sobre la Ley General de Estabilidad Presupuestaria", en Revista española de control externo, núm. 10, 2002, 15 y ss.

DE LA HUCHA CELADOR, F., "La reforma del artículo 135 de la Constitución: Estabilidad presupuestaria y deuda pública”, en Revista Española de Derecho Financiero, núm. 153, 2012, 21 y ss.

DE LA HUCHA CELADOR, F., "Comentario al Artículo 135 de la Constitución", en CASAS BAAMONDE, M. E. Rodríguez Piñero y BRAVO FERRER, M. (coords.), Comentarios a la Constitución española, Madrid, $2009,2.049$ y ss.

DE MIGUEL CANUTO, E., "Constitucionalidad de la estabilidad presupuestaria: fundamentos", en Crónica tributaria, núm. extr. 2, 2012, 43 y ss.

DI PLINIO, G., Il common core della deregulation. Dallo Stato regolatore alla Costituzione economica sovranazionale, Milano, 2005.

ESCRIBANO LÓPEZ, F., "La autonomía financiera de las comunidades autónomas: crisis económica, estabilidad presupuestaria y sostenibilidad financiera", en Revista española de derecho financiero, núm. 156, 2012,11 y ss.

GALÁN GALÁN, A., "La aplicación autonómica de la Ley de Racionalización y Sostenibilidad de la Administración Local", en Revista de Estudios de la Administración Local y Autonómica (nueva época), núm. extraordinario, enero, 2015, 1 y ss. https://doi.org/10.24965/reala.v0iextra.10225.

GALÁN VIOQUE, R., "La Administración General del Estado", en GOSALBEZ PEQUEÑO, H. (dir.), El nuevo régimen jurídico del sector público, Madrid, 2016, 153 y ss.

GALÁN VIOQUE, R., La responsabilidad del Estado legislador, Barcelona, 2001, espec. 209 y ss.

GARCÉS SANAGUSTÍN, M., "En torno al concepto de estabilidad presupuestaria en España", en GARCÉS SANAGUSTÍN, M. (coord.), La estabilidad presupuestaria en el Derecho español, Madrid, 2004, 19 y ss., espec. 27 y sS.

GARCÍA-ANDRADE GÓMEZ, J., "La reforma del artículo 135 de la Constitución española”, en Revista de Administración Pública, núm. 187, enero-abril, 2012, 31 y ss.

GARCÍA-ESCUDERO MÁRQUEZ, P., "La acelerada tramitación parlamentaria de la reforma del artículo 135 de la Constitución”, en Teoría y Realidad Constitucional, núm. 29, 2012.

GARCÍA ROCA, J., "El principio de estabilidad presupuestaria y la consagración constitucional del freno al endeudamiento", en Crónica presupuestaria, 1, 2013, 40 y ss.

GARCÍA ROCA, J. - MARTÍNEZ LAGO, M. A., "La repentina constitucionalidad de la Ley de estabilidad presupuestaria según la STC 215/2014, de 18 de diciembre", en Civitas. Revista española de derecho europeo, núm. 54, 2015, 89 y ss.

GONZÁLEZ BUSTOS, M. A., "Principios de buena regulación y evaluación de su cumplimiento", en GAMERO CASADO, E. (coord.), Tratado de procedimiento administrativo común y régimen jurídico básico del sector Público, Valencia, 2016, 2.539 y ss., 2.561.

GRASSO, G., Il costituzionalismo della crisi, Napoli, 2012, espec. 93 y ss.

GUERRERO VÁZQUEZ, P., "Freno al endeudamiento autonómico y coerción estatal en la ley orgánica de estabilidad presupuestaria y sostenibilidad financiera”, en Revista General de Derecho Constitucional, núm. 23, 2016.

LÓPEZ AGUILAR, F., "De la Constitución «irreformable» a la reforma constitucional «exprés»", en Teoría y Realidad Constitucional, 29, 2012, 199 y ss.

MANGIAMELI, S., "Crisi economica e distribuzione territoriale del potere politico (relazione introduttiva al XXVIII Convegno annuale dell'Associazione italiana dei costituzionalisti)", en Rivista AIC, 4, 2014, espec. 1-19. 
MANGIAMELI, S., Le Regioni italiane tra crisi globale e neocentralismo, Milano, 2013, espec. 39 y ss.

MARTÍNEZ LAGO, M. A., "Constitucionalización del principio de estabilidad presupuestaria en la Unión europea y en España. La Ley Orgánica de Estabilidad Presupuestaria y Sostenibilidad Financiera”, en GARRIDO, D. L. MARTÍNEZ ALARCÓN, M. L. (coords.), Reforma constitucional y estabilidad presupuestaria, Madrid, 2013,131 y SS., $153-154$.

MARTÍNEZ LAGO, M. A., "Crisis Fiscal, Estabilidad presupuestaria y reforma Constitucional”, en El Cronista del Estado Social y Democrático de Derecho, núm. 24, 2011, 10 y ss., espec. 17.

MEDINA GUERRERO, M., "La constitucionalización del principio de estabilidad presupuestaria”, en Revista de Estudios Regionales, núm. 105, 2016.

MEDINA GUERRERO, M., "El Estado autonómico en tiempos de disciplina fiscal”, en Revista Española de Derecho Constitucional, núm. 98, mayo-agosto, 2013.

MEDINA GUERRERO, M., “La reforma del artículo 135 CE”, en Teoría y Realidad Constitucional, núm. 29, 2012.

MEDINA GUERRERO, M., "La constitucionalización de la regla del equilibrio presupuestario: integración europea, centralización estatal”, en Revista de Estudios Políticos (nueva época), núm. 165, julio-septiembre, 2014,189 y ss.

ORDÓÑEZ SOLÍS, D., “¿Cómo se derivan entre las Administraciones españolas las responsabilidades financieras por el incumplimiento del derecho de la Unión europea?”, en Revista de Derecho comunitario europeo, núm. 51, mayo-agosto, 2015, 537 y ss.

PEMAN GAVIN, J. M., "Crisis económica y cambios institucionales en Europa y en España", en EZQUERRA HUERVA, A. (coord.), Crisis económica y Derecho Administrativo, Cizur Menor (Navarra), 2016, 27 y ss., 57.

RIDAURA MARTÍNEZ, M. J., "La reforma del artículo 135 de la Constitución española: ¿pueden los mercados quebrar el consenso constitucional?", en Teoría y Realidad Constitucional, núm. 29, 2012.

RODRÍGUEZ BEREIJO, A., La Constitución fiscal de España. Tres estudios sobre Estado social de Derecho, sistema tributario, gasto público y estabilidad presupuestaria, Madrid, 2005.

RODRÍGUEZ BEREIJO, A., La reforma constitucional del artículo 135 CE y la crisis financiera del Estado, Madrid, 2005.

RUIZ ALMENDRAL, V., "La reforma Constitucional a la luz de la estabilidad presupuestaria", en Cuadernos de Derecho Público, núm. 38, septiembre-diciembre, 2009, 89 y ss.

RUIZ TARRÍAS, S., "De la discusión sobre un «título competencial» a la afirmación de un «mandato constitucional»", en Revista Española de Derecho Constitucional, núm. 100, enero-abril, 2014, 331 y ss.

SAITTO, F., "«Costituzione finanziaria» ed effettività dei diritti sociali nel passaggio dallo «Stato fiscale» allo «Stato debitore»", en Rivista AIC, 1, 2017, espec. 2 y ss.

SALAZAR BENÍTEZ, O., "La Constitución domesticada: algunas reflexiones críticas sobre la reforma del artículo 135 CE”, en Teoría y Realidad Constitucional, núm. 29, 2012, 409 y ss., 414.

TEJERIZO LÓPEZ, J. M., "Comentario al Artículo 135: Deuda Pública", en ALZAGA VILLAAMIL, O. (coord.), Comentario a la Constitución española del 1978, Madrid, 1996, 345 y ss.

URÍA FERNÁNDEZ, F., "Una sentencia oportuna e imprescindible. Comentario a la sentencia 134/2011, de 20 de julio, del Tribunal Constitucional, sobre determinados preceptos de las leyes de estabilidad presupuestaria", en García de ENTERRÍA MARTÍNEZ-CARANDE, E. - ALONSO GARCÍA, R. (coords.), Administración y justicia un análisis jurisprudencial, Madrid, 2012, 373 y ss.

URRUTIA LIBARONA, I., "Crisis económica, estabilidad presupuestaria y recentralización de competencias", en NOGUEIRA LÓPEZ, A. - LOIS GONZÁLEZ, M. I. - DIZ OTERO, I. (coords.), Crisis, Derechos Sociales e Igualdad, Valencia, 2015. 